\title{
LA CRISIS LATENTE DEL DARWINISMO ${ }^{1}$
}

\author{
Maurício Abdalla \\ Universidad Federal do Espíritu Santo - Brasil
}

\section{RESUMEN}

El presente artículo analiza el paradigma darwinista en las ciencias biológicas a partir de la pregunta sobre su capacidad de explicar satisfactoriamente los nuevos datos obtenidos de la bioquímica, la microbiología y la genética. El objetivo general del análisis es contribuir con una discusión acerca del estado de las teorías científicas y el objetivo específico es reflexionar sobre una posible crisis del paradigma darwinista, lo que corroboraría la concepción de las teorías científicas como algo históricamente transitorio y no como descubrimientos definitivos.

PALABRAS CLAVE: Darwinismo; selección natural; evolución; teoría sintética; endosimbiosis; Michael Behe; Lynn Margulis; Máximo Sandín.

\begin{abstract}
In this article I will be analyzing the Darwinist paradigm in the biological science, discussing its capacity to give satisfactory understanding of the new data from biochemistry, microbiology and genetics. The general aim of this analysis is to contribute for the debate about the statute of the scientific theories. Its specific aim is to reflect upon a possible crisis of the Darwinist paradigm, which could corroborate the conception of scientific theories as something historically transitory, and not as definitive discoveries.
\end{abstract}

KEY WORDS: Darwinism; natural selection; evolution; synthetic theory; endosymbiosis; Michael Behe, Lynn Margulis, Máximo Sandin.

\section{INTRODUCCIÓN}

La cuestión central que deseo abordar en este artículo puede ser expresada de la siguiente manera: ¿Será Darwin para el siglo veintiuno lo que Newton fue para el siglo veinte? Se pretende hacer una investigación acerca de los límites de una teoría científica bien establecida a partir de su capacidad de

1 Traducido del portugués por Guillermo Agudelo. 
enfrentar los problemas que trae consigo el desarrollo de la ciencia. Como telón de fondo de esta discusión está el (ya viejo, pero aún actual) problema del estatus de la ciencia como portadora de una verdad definitiva acerca del mundo o como una construcción racional útil, aunque provisional, que entabla un diálogo dinámico entre la subjetividad humana y el mundo natural.

No hay elementos suficientes, en estos días, que nos permitan dar una respuesta categórica a esta cuestión, pero innumerables hechos nos proveen de argumentos para un debate sobre la importancia y oportunidad de, al menos, ponerla en discusión. A pesar de que el paradigma darwinista está sólidamente establecido en las ciencias biológicas, hay varias pistas que sugieren que determinados campos de investigación pueden forzarlo a un punto de tensión del cual o saldrá victorioso y robustecido, o pasará a la historia como un paradigma superado. El propósito del presente artículo es mostrar que, a pesar de la hegemonía conquistada por el darwinismo, recientes investigaciones han creado cierto clima de sospecha e insatisfacción a su alrededor.

El darwinismo siempre tuvo opositores y siempre estuvo sometido a cuestionamientos de diversos órdenes. Pero los desafíos actuales son substancialmente diferentes por estar relacionados con los avances del propio conocimiento científico en niveles de la realidad de la vida desconocidos hasta hace relativamente poco tiempo y que presentan fenómenos que desafían la estructura fundamental de la teoría darwinista.

\section{ACLARACIÓN DE LA METODOLOGÍA}

Para la presente reflexión partiré de la descripción de ciencia ofrecida por Thomas Kuhn². Para Kuhn, la historia de las ciencias puede ser interpretada como el proceso en el cual modelos científicos generales - con sus hipótesis, formas de experimentación y leyes (reunidos bajo el concepto de paradig$m a$ - conquistan una hegemonía por un determinado periodo de tiempo, pero son colocados a prueba por anomalías que, teniendo la fuerza necesaria para provocar una crisis, pueden impulsar nuevas proposiciones a partir de las cuales surge un nuevo paradigma hegemónico. A este proceso de cambio de paradigma, Kuhn lo denominó «revolución científica».

2 KuHN, T. (1979a), Lógica da descoberta ou psicologia da pesquisa. In: LAKATOS, I. \& Musgrave, A (1979), A crítica e o desenvolvimento do conhecimento científico. São Paulo, Cultrix/Editora da USP, p. 5-32; KUHN, T. (1979b), Reflexões sobre os meus críticos. In: idem, p. 285-343; KUHN, T. (1997), A estrutura das revoluções cientifica. São Paulo, Perspectiva. 
A pesar de lo que el término «revolución» pueda evocar, la idea no es de una transición abrupta y visible. Estando la realidad compuesta de muchos más elementos de los que pueden caber en nuestras descripciones, algunas de sus facetas pueden huir del paradigma dominante. En este caso, o esta faceta se mantiene como una anomalía tolerable o puede ser lo que dispare una crisis. La física del siglo XX nos ofrece los ejemplos necesarios de anomalías que fueron resueltas con la aparición de una nueva e insólita descripción de la naturaleza, la mecánica cuántica. Cuando una anomalía se vuelve intolerable (en el caso de la física, un caso emblemático fue el problema de la «radiación del cuerpo negro») es necesario el surgimiento de nuevas hipótesis, generalmente con carácter heterodoxo. Una de ellas se acaba volviendo paradigmática y, posteriormente, hegemónica, sustituyendo al paradigma anterior.

Siempre que se siga escrutando la naturaleza, y para eso se desarrollen instrumentos, experimentos y modelos teóricos cada vez más refinados y de mayor alcance, es normal que se revelen nuevos fenómenos. Muchas veces se descubre una dimensión totalmente nueva del Universo. Sería un exceso de soberbia creer que este nuevo campo antes inexplorado tenga que, necesariamente, someterse a las leyes de la teoría vigente. La historia de las ciencias nos sugiere que es necesario tener siempre guardado un extra de humildad para que nos enfrentemos a un Universo multidimensional que se rehúsa a limitarse a lo que sabemos sobre él.

La transición de paradigmas en las ciencias no sucede, con todo, como un gentil acuerdo de caballeros entre los científicos. La polémica que acompaña una crisis de paradigma extrapola muchas veces el restringido ámbito de las discusiones científicas. Una revolución científica es un acontecimiento histórico e invisible ${ }^{3}$. Ésta es una observación importante para comprender el carácter histórico de una posible crisis del paradigma darwinista que será discutida aquí.

El siglo XX fue marcado por la debacle de la física de Newton. Su falla como descripción general de la naturaleza se hizo evidente cuando se presentaron dos niveles de realidad antes desconocidos: el mundo del átomo y el campo de grandes velocidades y grandes masas. Los cambios de concepción de la naturaleza, trazados por la mecánica cuántica y por la teoría de la relatividad, fueron enormes. Sin embargo, una concepción más profunda de la cosmovisión mecánica determinista y reduccionista (con raíces en Descartes y Newton) acabó sobreviviéndole. La creencia de Laplace - de que todo el comportamiento del Universo podría ser previsto en su evolución temporal a

3 KUHN (1997), p. 173-181. 
partir de los datos acerca de las condiciones iniciales de sus partículas componentes y del conocimiento de las leyes de Newton - no fue totalmente desbancada por la física cuántica. Esta creencia revela no tanto una presunción triunfalista, sino una concepción metacientífica según la cual el comportamiento de la totalidad del universo y de totalidades locales es siempre un resultado de la suma de las características de cada elemento de este todo, sometidos a leyes conocidas que regulan el comportamiento de cada parte. Este reduccionismo (el todo se reduce a la suma de las partes) conduce a un determinismo (conociendo las partes y las leyes a las que están sometidas, se conoce el todo y su evolución temporal). Por esto, tal concepto trae la idea de previsibilidad en principio, cuya concretización dependería tan sólo del conocimiento detallado de cada parte del todo. Este reduccionismo caracteriza también a las ciencias biológicas y se manifiesta principalmente en la tentativa de hacer derivar toda la complejidad de la vida de la interacción mecánica de sus moléculas fundamentales, principalmente los ácidos nucleicos (ADN y ARN).

La mecánica cuántica introduce un elemento de incertidumbre - el llamado "principio de incertidumbre» de Heisenberg - que restringe la precisión absoluta de las mediciones e introduce un elemento de probabilidad en la mecánica. Pero se trata de una probabilidad totalmente controlada y expresada en una ecuación dinámica que permite prever los resultados probables (la ecuación de Schrödinger). El determinismo expresado en términos de probabilidad se diferencia del determinismo absoluto de Laplace, sin embargo no llega a postular el carácter totalmente imprevisible de los fenómenos.

Pero este último baluarte del paradigma newtoniano cedió cuando nuevas áreas de investigación fueron demostrando que el comportamiento de sistemas complejos no se podía reducir a la suma lineal de las propiedades de sus componentes. El «todo» de esos sistemas no era susceptible de un estudio que los considerara como una estructura aislada de la interdependencia de todos sus elementos constituyentes. En otras palabras, esta interdependencia entre los componentes y su comportamiento conjunto, y no cada uno de ellos separadamente, era lo que podría llevar a la comprensión de las propiedades de la totalidad que ellos mismos componen. En términos aproximados, lo que se afirma aquí es que el comportamiento del todo no puede ser reducido a una mera superposición lineal de los comportamientos de sus partes.

Los sistemas complejos no pueden ser sometidos a un procedimiento analítico reduccionista, al estilo cartesiano, pues su comportamiento emerge justamente del hecho de que constituyen una totalidad interdependiente y no de las propiedades de cada elemento en particular. Este cambio de perspectiva arrojó inmediatamente luz sobre el estado de los sistemas vivos, que se com- 
portan como sistemas complejos que de ninguna manera pueden ser reducidos a las propiedades de sus elementos (las moléculas orgánicas). Una de las facetas de la posible crisis de paradigma en la biología (que veremos en este artículo) está relacionada directamente con esta reflexión sobre la complejidad. El paradigma neodarwinista acabó por conducir a un enfoque reduccionista que cree que la vida es un resultado de fenómenos localizados en la molécula de ADN, sometidos al azar y a la selección natural. Enfoques más recientes apelan a las teorías de la complejidad para escapar de las dificultades que conlleva el análisis reduccionista cuando se compara con los fenómenos reales.

A partir de los conceptos básicos presentados arriba, el presente artículo procura analizar algunos problemas que la teoría darwinista enfrenta hoy en día de acuerdo a lo que ya se conoce sobre el funcionamiento de los organismos vivos. Algunas cuestiones guiarán el análisis siguiente: ¿Las últimas décadas de investigación en las ciencias biológicas revelan anomalías relevantes para la teoría darwinista? ¿Estas anomalías pueden ser incorporadas a la teoría dominante o al menos convivir con ella como anomalías tolerables? ¿Somos testigos de una transición de paradigma que asignará a Darwin la misma posición de honor que ahora ocupa Newton?

\section{LA LUZ DE DARWIN}

En la época de Darwin, la evolución de las diversas formas de vida no era un hecho desconocido. Darwin no «descubrió» el fenómeno de la evolución. No se conocía, sin embargo, qué tipo de mecanismo dirigía esta evolución y por qué las especies cambiaban con el tiempo, mientras otras aparecían. Una vez que el estudio de los fósiles y de la anatomía de los seres vivos fue revelando datos antes desconocidos, la idea de inmutabilidad de las especies fue paulatinamente derribada. Esto generó, en consecuencia, la necesidad de un nuevo enfoque científico que explicara el mecanismo y la razón de los cambios evolutivos. Naturalistas anteriores a Darwin, como Jean Baptiste de Lamarck y Georges Cuvier, entre muchos otros, se lanzaron sobre este desafío y buscaron explicaciones naturalistas para este fenómeno. Darwin fue uno más de ellos. Es probable que su triunfo se deba al hecho de que las condiciones para su teoría de la evolución estaban ya bien cimentadas.

Cuando digo que las condiciones estaban cimentadas no estoy afirmando que la teoría ya estaba «a punto de ser descubierta» gracias a los avances de la ciencia. Me refiero a las condiciones no sólo en cuestión de los datos disponibles en aquel tiempo sino también al «espíritu de la época» (Zeitgeist). El 
mecanismo de la teoría de la evolución de Darwin ya existía tanto en las teorías sociales de Malthus y Spencer como en el liberalismo clásico. O sea, había una predisposición social para ese tipo de teoría de la evolución. La creación de la teoría de la evolución por selección natural fue conducida por el desafío presentado por el conocimiento de hechos de la naturaleza otrora ocultas a simples observaciones e incomprendidas a la luz de las teorías vigentes, pero reproduce también la forma de pensar de la época.

A pesar de haber tenido un éxito estruendoso, la aceptación de la teoría de Darwin como paradigma científico hegemónico no fue inmediata. Decir que solamente fue una resistencia fundamentada en dogmas religiosos es un reduccionismo que menosprecia la influencia del espíritu humano en la realización histórica de la ciencia. La teoría de Darwin, en su expresión original, poseía lagunas enormes y, en su «estado puro», no explicaba una serie de complejidades encontradas en los organismos (en el caso de los microscópicos) y no se adecuaba al registro fósil disponible en la época (y menos al actual). Por tanto, no era sólo una doctrina que se oponía al creacionismo ingenuo, sino una teoría, de inicio, científicamente problemática ${ }^{4}$. Sin embargo, hoy en día el darwinismo no se puede restringir a los escritos de Darwin. Aun con todos los problemas exhibidos por El origen de las especies (por ejemplo, el desconocimiento del mecanismo de la herencia y la inadecuación al registro fósil), esta obra construyó la base para un nuevo paradigma que fue orientando a las ciencias de la vida como un poderoso programa de investigación. El darwinismo sólo triunfó como paradigma hegemónico en la forma de neodarwinismo o «Teoría sintética moderna». El paradigma dominante en las ciencias biológicas, hoy, es el neodarwinismo y no simplemente las proposiciones originales de Darwin. Hablar de darwinismo hoy es hablar de «síntesis moderna».

La estructura central de la teoría darwinista de la evolución, de acuerdo con Gould, se compone de tres ejes básicos: «1. Los organismos varían y estas variaciones son heredadas (por lo menos en parte) por sus descendientes. 2. Los organismos producen más descendientes que aquellos que pueden sobrevivir. 3. La media, la descendencia que varía con más intensidad en direcciones favorecidas por el medio ambiente, sobrevivirá y se propagará. Las variaciones favorecidas, por lo tanto, crecerán en población a través de la selección natural» ${ }^{5}$.

4 Thuillier, P. (1994). De Arquimedes a Einstein: a face oculta da invenção científica, Rio de Janeiro, Jorge Zahar, p. 189-220.

5 Gould, S.J. (1999), Darwin e os grandes enigmas da vida, São Paulo, Martins Fontes, p. 1. 
El primer eje introduce un aspecto no direccional en la evolución de los organismos que es neutralizado por el tercero. La selección natural depura el aspecto aleatorio de las mutaciones y les imprime dirección. El segundo eje es, conforme al propio Darwin, una aplicación de la teoría de Malthus a los reinos animal y vegetal, de acuerdo con la cual el crecimiento de la población no es acompañado por el crecimiento de los recursos disponibles; así, se torna necesaria una limitante natural que bloquee el crecimiento poblacional (epidemias, dolencias ocasionadas por el hambre y las guerras) o la intervención mediante controles de natalidad en las poblaciones pobres. Darwin cita a Malthus dos veces en El origen de las especies, una en la introducción y otra en el capítulo 3 («La lucha por la supervivencia»). En ambas referencias, Darwin dice textualmente que su idea «es la doctrina de Malthus aplicada a la totalidad de los reinos animal y vegetal» ${ }^{6}$.

Como consecuencia de estos ejes en su comprensión del origen de las especies, Darwin ve en la naturaleza una constante lucha por la supervivencia, cuyos vencedores eran agraciados con la posibilidad de tener una mayor prole. Esta idea generó una imagen de la naturaleza «roja en dientes y garras» de los naturalistas del siglo XIX. Ciertamente inspirado por Malthus, Spencer y la teoría económica liberal, Darwin vio en la naturaleza una competencia por la supervivencia, dada la escasez de recursos ante el crecimiento de la población ${ }^{7}$. El darwinismo, por lo tanto, es una teoría que propone la competencia como el motor que propulsa el desarrollo de las especies, pues la selección natural ocurre no solamente influida por su relación con el ambiente físico sino también con individuos de su misma especie y sus depredadores.

Darwin no poseía las informaciones que hoy tenemos acerca de las mutaciones y de los mecanismos de la herencia. La teoría sintética, o neodarwinismo, da como razón de las mutaciones los cambios aleatorios que ocurren en el código genético, o sea, se trata de variaciones moleculares. Esta adición refuerza dos otras implicaciones de los ejes darwinistas, el gradualismo de las mutaciones (las mutaciones no pueden ocurrir súbitamente ni a través de saltos) y la ausencia de un principio causante de los cambios (todo ocurre por el más absoluto azar; y no hay ningún principio que cause las mutaciones que pueda ser clasificado y convertirse en un concepto dentro de la teoría).

6 Darwin, C. (2005). A origem das espécies, São Paulo, Martin Claret, p. 66 e 126. En el texto original, tanto en la introducción como en el capítulo 3, Darwin anota acerca de su propuesta: «This is the doctrine of Malthus, applied to the whole animal and vegetable kingdoms».

7 Además de reconocer la aplicación de la teoría de Malthus a la naturaleza, Darwin cita a Spencer 5 veces en El origen de las especies, en los capítulos 1, 3, 4, 9 e 15. 
Pero el registro fósil, una de las bases empíricas imprescindibles de cualquier teoría de la evolución, no revela ese gradualismo. Lo que demuestra son largos periodos de éstasis, durante los cuales las especies se mantienen sin tener cambios significativos, seguidos de eventos de extinción en masa y el surgimiento brusco de nuevas especies. Gould y Eldredge propusieron que este patrón revela lo que ocurre de hecho en la evolución y llamaron a su modelo «equilibrio puntuado» ${ }^{8}$. Pero, aunque en este modelo la evolución pasa por periodos de cambios «rápidos» seguidos de largos periodos de estasis la expresión «rápido» sólo tiene sentido en términos geológicos y puede representar millones de años. Aun así, las mutaciones ocurren paso a paso en los individuos de una parte aislada de la población mayor. Segun Gould su visión defiende los «cambios espasmódicos o episódicos, preferentemente a un ritmo suave y gradual $\rangle^{9}$. De esta forma, el darwinismo se adapta a una de sus bases empíricas en conflicto (el registro fósil) sin comprometer sus principios fundamentales.

El problema relacionado con la improbabilidad de que se formen estructuras complejas al azar es anulado por las escalas temporales que plantea la evolución, contada en miles o centenas de millones de años (lo que daría tiempo suficiente, según algunos, para que acontecieran eventos improbables), y por el factor de limitación de la aleatoriedad que representa la selección natural.

De esto se deriva una otra importante implicación de los ejes de la teoría darwinista: el papel exclusivo de la selección natural en el mantenimiento de las variaciones. No puede haber intencionalidad ni reglas que afecten los cambios que prevalecieron en el mundo vivo. Es tan sólo la mayor aptitud de un organismo para sobrevivir en su medio y el vencer en la lucha por la supervivencia lo que decidirá cuáles variaciones prevalecerán a través de la generación de un mayor número de descendientes. La naturaleza lleva a cabo todo el papel. Por lo tanto, para que se puedan formar organismos complejos a partir de pequeñas mutaciones aleatorias, la selección natural es un hecho imprescindible en la constitución de una nueva especie. Ella actúa (en teoría) como un motor del proceso evolutivo. Por eso, todo paso intermedio probable

8 Gould, S. J. \& Eldredge, N. (1972), «Punctuated equilibria: an alternative to phyletic gradualism». In: SCHOPF, T. J. M. (1972.). Models in paleobiology, San Francisco, Freeman, Cooper and Co., p. 82-115; GolD, S.J. \& ELDREDGE (1993), «Punctuated equilibrium comes of age», Nature, 366, 223-227.

9 Gould, S.J. (1992), A galinha e seus dentes e outras reflexões sobre história natural, Rio de janeiro, Paz e Terra, p. 259. 
entre un ancestro simple y su descendencia más compleja debe presentar alguna ventaja selectiva. En la explicación evolutiva de organismos complejos, los pasos no pueden ser citados tan sólo como secuencias, sino que cada uno de ellos tiene que ser referido por su relación con la obtención de alguna ventaja selectiva. Si no se considera este factor, la explicación no preserva la teoría darwinista.

La teoría neodarwinista de la evolución fue aceptada como una teoría capaz de presentar un modelo mecanicista que posibilita la comprensión de la variedad de las especies, la razón de sus semejanzas, las causas de la diferenciación y el surgimiento de nuevas especies en clara descendencia de especies diferentes, sean actuales o extintas. A partir de los escritos de Darwin y tras su coronación como paradigma (en su versión moderna) prácticamente todas las ciencias de la vida fueron orientadas por una concepción evolucionista darwiniana. El paradigma darwinista fue (y es aún) un resonante éxito en la mayoría de la comunidad científica.

En comparación con los datos que se han acumulado en la actualidad, podemos decir que Darwin no tenía la menor noción de lo que ocurría en el interior de una célula y, naturalmente, no se podría esperar que su reflexión tratase de esa dimensión, hoy más conocida, de la realidad natural. Pero la investigación del mundo intracelular tuvo grandes avances en la segunda mitad del siglo diecinueve y durante todo el siglo veinte y reveló elementos completamente desconocidos para la ciencia. ¿Podrá el paradigma darwinista sobrevivir a ese nivel de la realidad, o estamos una vez más frente a un caso en el que el descubrimiento de nuevas dimensiones de la naturaleza exige la formulación de nuevas concepciones científicas?

\section{UN NUEVO MUNDO DENTRO DE LA CÉLULA}

La comprensión de que las células son las unidades básicas que componen todos los seres vivos data de la primera mitad del siglo diecinueve. Aun cuando no podamos atribuir el surgimiento de una teoría a simples aplicaciones de instrumentos adecuados a la observación (dado que los instrumentos no elaboran teorías), no se puede negar el hecho de que una teoría celular sobre la composición de un ser vivo solamente surgió cuando los sucesivos refinamientos de las capacidades de los microscopios revelaron dimensiones de la realidad antes ignoradas.

En la segunda mitad del siglo diecinueve ya se aceptaba que las células componían todos los tejidos y órganos, tanto de animales como de vegetales, 
y que el desarrollo embrionario ocurre por divisiones celulares. Sin embargo, no se tenía una idea clara acerca de qué sustancia forma la célula ni del tipo de interacción que ocurre en su interior. Algunos consideraban que la materia de la que estaban constituidas era de una naturaleza cualitativamente distinta a la que participaba en la composición de objetos inanimados, o que las fuerzas que determinaban el desarrollo de las células y la constitución de los organismos vivos eran externas al fenómeno. La célula, por tanto, era tan sólo un dato, pero poco conocido en su estructura interna. Incluso se pensaba que su estructura era mecánicamente simple, a partir de la cual podrían revelarse los secretos de la dinámica de los organismos vivientes.

Alrededor de la década de los 40 del siglo veinte, debido a la utilización del microscopio electrónico, se conocía ya algo más al respecto del núcleo y de algunos organelos, pero muy poco de la complejidad que hoy en día se reconoce. Mientras algunos sugerían una célula con una dinámica trazada por la interacción de moléculas comunes, organizadas de forma peculiar, otros todavía defendían la acción de un principio vital, a veces actuando sobre una materia diferente de las otras. El físico Erwin Schrödinger, famoso por la ecuación que describe la ley dinámica básica de la teoría cuántica, también fue notable por defender la idea de que la vida estaba básicamente constituida por moléculas comunes, dispuestas de una forma análoga a la de los cristales ${ }^{10}$. Aunque no había creado la idea, Schödinger elaboró argumentos lo suficientemente fuertes como para incitar a científicos a trabajar en la investigación de las dimensiones moleculares de la vida, esperando con ello entender la «química de la vida». La culminación de esta idea se dio en los trabajos de James Watson y Francis Crick, quienes usando métodos matemáticos e instrumentos avanzados de cristalografía por rayos X, revelaron, en 1953, la forma de la molécula responsable de la codificación de la estructura de los organismos vivos, el ácido desoxirribonucleico.

Durante toda la década de los 60, ocurrieron numerosos avances en la comprensión de la química de la vida. Algunas moléculas esenciales de la vida, como las bases nitrogenadas que componen los nucleótidos, fueron sintetizadas en experimentos de laboratorio, a través de reacciones químicas comunes. La síntesis de esas bases fue siempre de muy bajo rendimiento como para explicar el surgimiento de los ácidos nucleicos y el origen de la vida, pero contribuirían a confirmar el vínculo entre los procesos orgánicos y reacciones químicas entre los elementos conocidos.

10 Schrödinger, E. (1997), O que é vida?, São Paulo, Edunesp. 
Mientras tanto, el programa de investigación molecular de la vida no sólo fue revelando la estructura de las moléculas básicas de los procesos bioquímicos, sino también desmantelando la idea de que la célula era una unidad simple. Ésta es una cuestión importante. Se aprecia mucho una suerte de desencantamiento ocasionado por la revelación de que la vida es solamente una aglomeración de moléculas que funciona de una forma peculiar y está constituida básicamente de seis elementos: carbono, hidrógeno, oxígeno, nitrógeno, fósforo y azufre. La materia de la vida no tiene nada de extraordinario: se acabó el misterio. Sin embargo, tales moléculas y sus interacciones constituyen, en conjunto, un sistema altamente complejo y organizado, diferente de todo lo que la naturaleza nos había revelado hasta ese momento. Semejante organización e interdependencia de acción de los diferentes componentes que constituyen la estructura celular sólo son comparables con la dinámica organizadora de las grandes empresas humanas - siendo las tareas organizadas del hombre las que pierden en términos de complejidad, interacción y organización, aunque sean planeadas por seres conscientes. Mientras, hubo un desencanto en relación a «la materia» que constituye la vida, y aun permanece el misterio acerca de su «organización»y, principalmente, del «origen» de esta organización.

Los que defienden que las leyes simples de la química y de la física, aplicadas localmente, explicarían «todo» el funcionamiento de la célula parecen no considerar, por su reduccionismo, el problema de la complejidad y del orden que emergen de las interacciones moleculares en el interior de las células y de los organismos que componen. El conocimiento más profundo del funcionamiento de la vida, al mismo tiempo que desveló un misterio (la materia constituyente), sorprendió nuestro conocimiento al mostrar un comportamiento inusitado para una aglomeración de componentes químicos comunes (la organización compleja de esa materia).

El carácter complejo y organizado de las células se manifiesta en las intrincadas y altamente coordenadas interacciones entre las moléculas, que buscan mantener vivo un organismo, posibilitar su desarrollo mediante el metabolismo y la síntesis de proteínas y permitir su replicación con el mínimo de error posible. Esa complejidad queda oculta, la mayoría de las veces, en los relatos de algunos autores que procuran dar una explicación científica para el surgimiento y la evolución de la vida.

En lo que respecta a la vida, relatos simples y facilmente digeribles para el público general sólo son posibles cuando su complejidad es ignorada. El problema es que, si no se la considera, la «explicación» pierde su capacidad esclarecedora. Es esto lo que ocurre con la narrativa de científicos que buscan 
explicar el origen y la evolución de la vida sin considerar la complejidad del mundo celular. Es lo que hace, por ejemplo, Richard Dawkins cuando intenta describir un escenario probable para el surgimiento de las primeras células en El gen egoísta. Según él: «(Algunos) replicadores tal vez hayan "descubierto» cómo protegerse a sí mismos, ya sea químicamente o levantando una barrera fisica de proteina a su alrededor. Puede ser que asi hayan surgido las primeras células vivas. Los replicadores comenzaron no sólo a existir, sino a construir vehículos para la preservación de su existencia» ${ }^{11}$.

Este tipo de narrativa evoca la idea de que la síntesis de proteínas por genes es un proceso simple que no requiere de mayores explicaciones. Se sabe, no obstante, que la síntesis de proteínas es un proceso extremadamente complejo. La descripción de la evolución también debería de referirse a esa complejidad, procurando explicar cómo surge y se desenvuelve. Mientras tanto, gran parte de las descripciones evolucionistas, principalmente a las que tiene acceso el público general, suelen utilizar explicaciones simples para relatar el posible origen de las células a partir de mutaciones aleatorias y selección natural.

Una buena parte de estas explicaciones simplistas parten del gen como principal elemento de la vida, como si fuese posible entender el todo a partir de esta parte fundamental. Sin embargo, lo que la ciencia muestra es que un gen no es nada especial, a no ser que se inserte en una estructura celular e interactúe con otras moléculas. Sin su inserción en un todo interactuante, una molécula de ADN no contiene nada de información, es decir, no contiene «genes». El aspecto informativo de los genes sólo es posible en la descripción del observador, después de su inserción en una célula. El proceso de contenido informativo, por ejemplo, sólo comienza con la polimerasa ARN, creando un molde ARN del gen. Para que esto ocurra es necesario que intervengan otras enzimas con funciones de elección, reparación del ADN, corrección de errores, etc. No se trata de un simple proceso de conversión automática de una secuencia de letras en otra correspondiente. Las relaciones de decodificación de las informaciones genéticas en una célula constituyen un proceso intrincado donde las enzimas involucradas parecen «saber» lo que están haciendo o estar "programadas» para hacerlo. Eso jamás ocurriría mediante un simple amontonar de componentes a lo largo del tiempo.

Existe un factor que aumenta enormemente la complejidad de ese proceso. La mayoría de los genes (en el ser humano más del 64\%) está formada por ciertas secuencias de bases que serán usadas en la síntesis de la proteína (exo-

11 Dawkins, R. (1989) O gene egoísta, Lisboa, Gradiva, p.53. 
nes), intercalada en largos segmentos no codificadores (intrones). Eso dificulta el trabajo de identificación del gen y, al mismo tiempo, lo hace menos determinista. Diferentes exones de un mismo gen pueden ser ligados de forma diferente, lo que resulta en moléculas de ARN distintas y, consecuentemente, la producción de proteínas diversas a partir de un mismo gen, proceso conocido como «splicing alternativo».

La complejidad que emerge de la interacción molecular en organismos vivos y la imposibilidad de una creación por acumulación de partes se demuestra también en el hecho de que las enzimas son proteínas y, por esto, éstas son, al mismo tiempo, el producto final del proceso de síntesis proteica $y$ un componente activo para que tal síntesis ocurra. Asimismo, las uniones moleculares que forman las moléculas mayores que componen la vida dependen de catalizadores para llevarse a cabo ${ }^{12}$. Los catalizadores de las moléculas que forman el ARN y el ADN también son enzimas. Las proteínas, por lo tanto, se encuentran al inicio, en medio y al final del proceso de su propia producción.

Esta complejidad no es desconocida para quien estudia las ciencias de la vida: «Los procesos moleculares involucrados en la síntesis de proteinas en las células actuales parecen insolublemente complejos. Aunque comprendemos la mayoría de esos procesos, no presentan un sentido conceptual de la forma en que la trascripción, la reparación y la replicación del ADN se llevan a cabo. Es especialmente dificil de imaginar cómo evolucionó la síntesis de proteína, tomando en cuenta que hoy en día se realiza a través de un complejo sistema interconectado de moléculas de proteinas y $A R N \gg^{13}$.

No obstante, esto es soslayado por los biólogos que pretenden que el surgimiento de la vida y la complejidad de la célula parezcan algo obvio, inevitable, simple y capaz de ser descrito con un orden de pasos hipotéticos, resultantes de mutaciones aleatorias y selección natural. Richard Dawkins es un buen ejemplo (aunque no el único) de los que creen que especulaciones creativas pueden asumir el estatus de ciencia, tan sólo por el hecho de que se adhieren a los principios darwinistas, aunque no se refieran a nada que se pueda experimentar o cuya posibilidad de ocurrencia se pueda indicar materialmente. Él afirma: «La teoría de la evolución [...] de Darwin es satisfactoria porque nos muestra una forma a través de la cual la simplicidad se pudo haber

12 En verdad, se sabe que algunas de estas uniones pueden, en principio, realizarse sin catalizador, pero de forma extremamente lenta y con rendimiento muy bajo, lo que no permitiría la secuencia de pasos necesaria para la formación de la vida (Cf. DE Duve, C. (1997), Poeira vital, Rio de Janeiro, Campus, p. 32-35).

13 AlBerts, B. et. al. (2004), Biologia molecular da célula, Porto Alegre, Artmed. 
transformado en complejidad, cómo átomos desordenados pudieron agruparse en estructuras cada vez más complejas, hasta acabar formando personas. Darwin nos ofrece una solución, la única de entre todas las sugeridas, aplicable al cuestionamiento profundo de la existencia» ${ }^{14}$.

Dawkins parece ver las cosas de forma muy simple. Hasta para un observador ajeno a la ciencia pero con razonables conocimientos acerca de ella, queda evidente que la aseveración de Dawkins no se basa totalmente en datos científicos. La idea fundamental del autor de El gen egoísta es que la unidad básica de la vida es un replicador, que surgió de la tendencia a la estabilidad de ciertas aglomeraciones de átomos y que intenta, sea como fuere, reproducirse y perpetuarse. Dawkins afirma que el surgimiento de ese replicador no es ningún misterio sino el resultado de «procesos físicos y químicos vulgares». Faltaría saber si este «deseo» de reproducirse (que él caracteriza de «egoísta», selfish) puede ser el resultado de esos procesos físicos y químicos o es un atributo metafísico del replicador (ya que no puede ser psicológico).

Dawkins afirma con absoluta seguridad que el proceso vital se inicia cuando una aglomeración de moléculas con uniones estables adquiere la capacidad de autocopiarse, pero no dice nada sobre lo que sería necesario para esta autocopia. Después habla de la adquisición de una membrana, sin siquiera describir la estructura de una membrana funcional. Todo parece ser muy obvio y la descripción sigue una lógica perfectamente asimilable por cualquier lector. Sin embargo, el relato de Dawkins no solamente es especulativo, al no ser más que un relato semejante al que se hace en la ciencia ficción, donde el autor habla de las máquinas futuristas que permiten el teletransporte, la superación de la velocidad de la luz, etc., sin que haga falta la descripción de cómo ocurre todo esto. La diferencia aquí es tan sólo la dirección temporal: la ficción de Dawkins habla de cosas que «sucedieron» en el pasado, sin describir cómo es que pudieron haber ocurrido a la luz de los conocimientos actuales.

$\mathrm{Su}$ descripción ignora el hecho de que una molécula de ARN o de ADN no se forma sin la presencia de un catalizador. Jamás se podría conseguir un ácido nucleico por la sola aglomeración fortuita de átomos, dada cualquier condición. En la forma actual de la célula, las enzimas realizan la catálisis de los ácidos nucleicos. Arriba se mencionó el problema del carácter cíclico de este proceso. Dawkins, sin embargo, evita hablar de esta dificultad. Para él, los primeros replicadores se formaron simplemente sin la necesidad de proteínas. Intenta escapar de esta cuestión afirmando que es posible que los primeros replicadores no fuesen ácidos nucleicos, sino un «pariente» y que posterior-

14 DAWKINS (1989), p. 43. 
mente las «máquinas de supervivencia» fueron «tomadas» por el ADN (como de hecho dice en la obra citada). El problema es que, además de adjudicar el inicio de la vida a una entidad misteriosa e inexistente en la actualidad, sin mencionar un solo elemento químico que pudiera tener parte en ese replicador ancestral, su solución no responde al problema de la formación del ADN o del ARN. Acaba siendo tan científico como cuando se dice que alguna divinidad o fuerza misteriosa intervino en el proceso: ambas afirmaciones adjudican el problema a entidades que no son abordables por el método científico, ni experimental ni teóricamente.

Ninguna experiencia en el laboratorio corrobora esta visión simplista. El químico francés Auguste Commeyras cita la literatura especializada para ilustrar este hecho: «Es dificil, si no imposible, sintetizar largos polímeros de aminoácidos (péptidos o proteínas) o de ácidos nucleicos (ARN) en solución acuosa homogénea» ${ }^{15}$. La conclusión a la que se llega es que la «simplicidad» con que Dawkins trata la cuestión es una simplicidad tan solo retórica, pero poco tiene que ver con los problemas reales de la química de la vida.

Con el mundo ya descubierto que existe dentro de las células las explicaciones darwinistas simplistas pierden su capacidad esclarecedora. Por eso, la aplicación de la ortodoxia darwinista al origen de la vida y a su complejidad a nivel molecular resulta en narrativas que sirven tanto para organismos vivos como para máquinas construidas por seres humanos (automóviles, computadoras, aviones, etc.). La ciencia no puede contentarse con eso. La insatisfacción de algunos científicos puede ser expresada en las palabras de Margulis y Sagan: "Como una merienda azucarada que satisface temporalmente nuestro apetito, pero nos priva de una alimentación más nutritiva, el neodarwinismo sacia nuestra curiosidad intelectual con abstracciones desprovistas de detalles reales - sean metabólicos, bioquímicos, ecológicos o de historia natural» ${ }^{16}$.

Es a partir de esas cuestiones que se sitúa la pregunta sobre la crisis del darwinismo. A mi manera de ver es una cuestión muy actual. A pesar de lo incómodo que pueda ser para numerosos científicos y no obstante la defensa radical (no siempre racional, como veremos) que se hace de la plenipotencia del darwinismo, se trata aún de una cuestión abierta, sin decisión visible en las próximas décadas, pero que merece ser debatida.

15 Orgel, L. apud Commeyras, A. (2002), «A terra, matriz da vida». In: Morin, E. (2002) A religação dos saberes, Rio de Janeiro, Bertrand Brasil, p. 87.

16 Margulis, L \& Sagan, D. (2002a), Acquiring genomes, New York, Basic Books, p. 103. 


\section{Cuestionando a Darwin}

En El gen egoísta, Dawkins hace la siguiente afirmación: «Hoy la teoría de la evolución está tan sujeta a la duda como la teoría de que la Tierra gira alrededor del Sol.» ${ }^{17}$ Es evidente que con esto pretende decir que la teoría de la evolución (identificándola con el darwinismo) es algo incuestionable y que solamente es rechazada por quien está sujeto a dogmas de origen religioso superados. Al darle tal estatus a una teoría científica, Dawkins establece un concepto previo, no científico, que protege la teoría de cualquier debate que cuestione su validez, caracterizándolo como negación de lo obvio.

La intención de la afirmación de Dawkins es inmediatamente rechazada por quien tiene una visión histórica de la ciencia. Ninguna teoría puede considerarse definitiva, infalible o libre de dudas. Sin embargo, su frase, evaluada con un cierto rigor, revela lo que bien puede estar pasando con la teoría darwinista de la evolución. En primer lugar, Dawkins evoca una afirmación factual, la órbita de la Tierra alrededor del Sol, que después usa para hacer una analogía con una teoría que explica un hecho. Confunde hecho con teoría. La teoría de la evolución no es un hecho. La evolución sí puede ser concebida como tal. Por otro lado, el giro de la Tierra alrededor del Sol no es una teoría, sino una afirmación factual dentro de una teoría. Si admitimos que la órbita de la Tierra es un hecho incuestionable, no podemos hacer lo mismo con las teorías que explican la razón de esta órbita. En verdad, todo el esfuerzo de Galileo fue crear mecanismos teóricos que permitiesen que el movimiento de la Tierra fuese aceptado como un hecho, ya que no lo experimentamos en la vida cotidiana. Isaac Newton fue el responsable de la síntesis teórica que hace que la órbita de los planetas alrededor del Sol concuerde con la concepción común y se vuelve una afirmación factual. Recordemos que la teoría newtoniana fue acogida en los siglos dieciocho y diecinueve como una verdad definitiva y como un triunfo de la razón. Sin embargo, la teoría que explicaba la órbita de los planetas hasta el inicio del siglo veinte no sólo fue puesta en duda: en sus aspectos más generales y elementales se cae completamente. Hoy es el concepto de la gravitación de Einstein el que da la explicación para el mismo «hecho».

Por lo tanto, Dawkins acaba teniendo razón, diciendo lo que no quería. La evolución se considera un hecho desde el siglo dieciocho. La teoría que explica la evolución no puede ser identificada con el hecho de la evolución y, por consiguiente, si puede ser puesta en duda, tanto como lo fue la teoría que explicaba la rotación de la Tierra alrededor del Sol. Los cambios teóricos no significan cam-

17 DAWKins, R. (1989), p. 28. 
bios en aquello que damos como hechos bien establecidos. Como la afirmación de que la Tierra gira alrededor del Sol no se constituye, por sí misma, en una teoría, haremos un ligero añadido a la frase de Dawkins para iniciar la reflexión de esta sección: «Hoy la teoría de la evolución está tan sujeta a la duda como [lo estuvo] la teoría [que explicó por qué] la Tierra gira alrededor del Sol».

Esta duda no se refiere a la motivada por razones religiosas que, en mi opinión, ni siquiera debería ser parte de los debates científicos. La posibilidad de la duda a la que me refiero parte de las reflexiones internas de la ciencia. Lo inadecuado del paradigma darwinista al estudio del origen y de la complejidad de la vida ha sido presentado por diversos científicos (biólogos o no biólogos) y numerosas propuestas han sido creadas a partir de esto. Pocos, sin embargo, han demostrado interés en destacar claramente las contradicciones de sus reflexiones con los principios centrales del darwinismo moderno.

Otros, no obstante, expresan abiertamente su insatisfacción con el paradigma neodarwinista y hacen proposiciones alternativas en franca oposición a los dogmas dominantes. Hablaré a continuación de tres de ellos que se colocan explícitamente en contra del neodarwinismo, como es el caso del bioquímico Michael Behe (de la Universidad Lehigh, Pensilvania) y de los biólogos Lynn Margulis (de la Universidad de Massachussets) y Máximo Sandín (de la Universidad Autónoma de Madrid). Podría ciertamente recurrir a otros autores que han procurado utilizar enfoques de mayor amplitud que la teoría sintética moderna, incorporando elementos de la termodinámica, de las estructuras disipativas de Prigogine y de las recurrentes reflexiones sobre sistemas complejos, autoorganización y autopoiesis. Todas esas propuestas que intentan comprender teóricamente lo que los datos experimentales han revelado se alejan o, a veces, se colocan en contradicción con los principios básicos de la teoría sintética. Sin embargo, no todos los científicos han reflexionado sobre el conflicto de sus estudios con la teoría hegemónica y la «síntesis» corre el riesgo de perder su coherencia interna cuando solamente «incorpora» nuevos enfoques sin reflexionar sobre su relación con los principios generales que la sustentan. La razón, por lo tanto, de elegir a los tres citados es su franca y abierta oposición al paradigma dominante y el hecho de que sus estudios están bien fundamentados e instruidos en datos científicos de gran relevancia y actualidad.

\subsection{La crítica de Behe}

Michael Behe presentó sus reflexiones en un único y polémico libro, $L a$ caja negra de Darwin, así como en diversos artículos que giran en torno al 
mismo tema. Su crítica está bien fundamentada en análisis científicos a partir de su campo de estudio, la bioquímica, pero se encuentra aunada a la propuesta de un «diseñador inteligente» que sería el responsable de la complejidad de la vida. Quisiera aprovechar tan sólo su crítica y no meterme en una discusión acerca de esta propuesta ${ }^{18}$.

Sus objeciones al darwinismo no pueden ser descartadas, pues nos traen cuestiones que de hecho se convierten en un desafío para la teoría de la evolución. Ante los cuestionamientos científicamente fundados de Behe (es decir, no se trata de una crítica fundada en razones filosóficas o religiosas, a pesar de lo que pueda evocar la parte propositiva del libro) el darwinismo, o se muestra capaz de responder sin alterar los ejes fundamentales que lo caracterizan como paradigma, o debe resignarse a la condición de paradigma en crisis - o como un «programa de investigación degenerativo», usando el lenguaje de Lakatos. La ausencia de respuestas satisfactorias no significa ciertamente que la proposición de Behe sea correcta, sino el reconocimiento de la crisis del darwinismo y de la necesidad de una nueva teoría de la evolución.

Con todo, hasta donde pude analizar, la respuesta que dieron los darwinistas a Behe se puede dividir en tres posturas: 1) Los que claman contra la simple actitud de cuestionar la teoría darwinista, sin siquiera discutir las interrogantes presentadas - éstos tan solo arrojan las críticas de Behe al horno crematorio de las ideas creacionistas tradicionales o recurren a la retórica para contestarlas; 2) Los que ignoran totalmente la primera parte de La caja negra de Darwin y se limitan a disputar sus proposiciones del «diseñador inteligente» - es decir, atacan la parte «más débil»; y 3) Los que reconocen las críticas e intentan responderlas, pero que apenas reafirman su creencia doctrinaria en el darwinismo sin presentar nuevas proposiciones para solucionar las dudas derivadas del análisis de Behe. Por lo tanto, los problemas que Behe expone continúan siendo «anomalías» dentro del paradigma dominante.

Veamos, en resumidas cuentas, cuáles son los problemas propuestos por Behe. En primer lugar, coloca el problema en los mismos moldes de otros críticos de la ortodoxia darwinista: nuevos campos de fenómenos se han mostrado renuentes a adaptarse a la teoría evolucionista moderna: «Casi un siglo y medio después de que Darwin presentó su teoría, la biología evolutiva ha tenido mucho éxito al explicar los patrones de vida que vemos a nuestro alre-

18 Por otra parte, en toda respuesta de los darwinistas a lo que Behe califica de «reto de la bioquímica a la teoría de la evolución» (subtítulo de su obra), sólo encontré comentarios sobre su insólita proposición, reinando un absoluto silencio en lo que respecta a las críticas bien basadas que presenta al darwinismo. 
dedor. Para muchos, el triunfo es completo. Sin embargo, la verdadera obra de la vida no acontece a nivel animal o de órganos completos. Las partes más importantes de los seres vivos son demasiado pequeñas para ser vistas. La vida es vivida en los detalles y a las moléculas les toca encargarse de esos detalles. La idea de Darwin puede explicar los cascos de los caballos, pero ¿podrá explicar los cimientos de la vida?» ${ }^{19}$

Nótese que, a pesar de lo que afirman sus críticos, no ha hecho un cuestionamiento «de principio» o sobre la congruencia del darwinismo como descripción válida de la realidad. No obstante Behe afirma que éste se limita a un nivel de esa realidad. Desde ese punto de vista, su crítica se identifica como la reflexión sobre la crisis del paradigma hecha cuesta arriba y no posee el carácter de un cuestionamiento que tiene como base principios religiosos. Los biólogos darwinistas dedicaron su atención al mundo macroscópico y a la evolución de los mamíferos, pero no reflexionan acerca de los cimientos de la vida, que son microscópicos, moleculares.

En el mundo de la bioquímica las cosas adquieren un grado de complejidad sin ninguna analogía posible en el mundo macroscópico. Para Behe, esa complejidad no se puede haber formado por mutaciones aleatorias graduales en el código genético y por selección natural. Para sustentar esta afirmación, utiliza el concepto de complejidad irreducible, con el que se refiere a los sistemas compuestos por varias partes que interactúan y cuya funcionalidad depende de la presencia y acción de todas las partes al mismo tiempo. Si falta una de la partes de un sistema irreduciblemente complejo éste será, por definición, no funcional. Un sistema irreduciblemente complejo no puede tener fases intermedias «funcionales». Si éste fue producido por algún ser inteligente, como en el caso de una ratonera (ejemplo que utiliza Behe), una constitución por etapas será mantenida por la intención del productor. Pero en una naturaleza no intencional las fases intermedias no funcionales carecen de una razón para perdurar y esperar a que se les otorgue un «toque final» que les permita acceder a su funcionalidad, ya que la naturaleza sólo selecciona sistemas funcionales capaces de dotar a un organismo de alguna ventaja para la supervivencia ${ }^{20}$.

Con base en esta premisa, Behe defiende la idea de que, analizados a un nivel bioquímico, los principales procesos que sustentan la vida (la síntesis de proteínas, el sistema de coagulación sanguínea y el sistema inmunológico) y los órganos complejos como el ojo, el flagelo bacteriano y la membrana celu-

19 BeHE, M. (1997a) A caixa preta de darwin, Rio de Janeiro, Jorge Zahar, p. 14.

20 BEHE, M. (1997a), p. 48. 
lar son procesos y órganos irreduciblemente complejos, por lo que no pueden ser explicados mediante las mutaciones aleatorias graduales mantenidas por la selección natural. Esta reflexión es apoyada por numerosos datos científicos de precisión hasta ahora no cuestionados, lo que marca su diferencia principal con las narrativas darwinistas (como la de Dawkins, arriba citada) que se sustentan gracias a la precisión lógica, matemática y retórica cuando pretenden explicar la evolución de complejidad bioquímica y microbiológica.

Uno de los procesos que Behe analiza para caracterizarlo como irreduciblemente complejo es el sistema de coagulación sanguínea. Este proceso ocurre en forma de cascada: cuando es activado por un corte $\mathrm{u}$ otro proceso que provoque sangrado, se desencadena un conjunto de acciones generadas por varios tipos de proteínas y enzimas que a sus vez activan a otras proteínas y enzimas y así sucesivamente hasta que producen como resultado final una coagulación controlada, evitando tanto una hemorragia como una trombosis. Si falta alguno de los elementos de esa cascada se puede generar una hemorragia descontrolada o una trombosis general. Una narrativa darwinista imaginaria podría limitarse a decir que la adquisición de un precursor del sistema de coagulación, ocasionada por una pequeña mutación aleatoria en el ADN o por una duplicación de genes, ofreció una ventaja selectiva a un ancestro remoto de los actuales animales y que por eso fue mantenida. Después, sucesivas mutaciones ocasionales (siempre al azar) fueron mejorando ese sistema, aumentándole una que otra proteína hasta llegar al sistema actual.

Behe presenta muchas razones para no aceptar, de manera alguna, esa narrativa. Emplea 12 páginas intentando explicar, de forma simplificada, el funcionamiento de esa cascada, buscando revelar al lector aquello que normalmente se oculta tras expresiones como «un sistema más simple» o «el aumento de una proteína». Para tener una vaga idea, al menos, de lo que el proceso de coagulación sanguínea implica es necesario conocer los datos reales que la bioquímica revela.

La fibrina es la proteína responsable de la formación de un coágulo, pero la adquisición de esta proteína por una mutación al azar no traería ninguna ventaja a un organismo, pues generaría una coagulación generalizada y fuera de control. Por ello se encuentra presente en el organismo en forma inactiva (fibrinógeno). El fibrinógeno debe ser activado por la trombina. Por razones obvias, la trombina también debe estar inactiva (como protrombina) y ser activada en el momento en el que sea necesaria la coagulación. La activación de la trombina requiere del factor Stuart-Prower y de la acelerina. Cierta cantidad de proteínas se requieren para activar el factor Stuart-Prower y éste, a su vez, sólo podrá activar a la trombina en presencia de la acelerina. La proteína 
responsable de la activación de la acelerina será la trombina. Queda evidente el carácter cíclico del sistema, una de las características de los sistemas complejos. Sin embargo, la cascada involucra otras proteínas como el factor de Hageman, la HMK, la calicreína, la PTA, la convertina, el factor de Christmas, el factor anti-hemofílico (que es activado por la trombina de forma semejante a lo que acontece con la proacelerina), que actúan en la activación del factor Stuart-Prower.

Es la acción de todas estas proteínas en conjunto que permite la formación de un coágulo tan pronto como se presenta un sangrado, es decir, en el único caso en el que puede aportar una ventaja para el organismo. La ausencia de cualquiera de una de ellas en el sistema lo vuelve no funcional. Además, para que el proceso de coagulación no continúe hasta generar una trombosis generalizada es preciso que el sistema se encuentre balanceado. Para esto, son necesarias otras proteínas que actúen conjuntamente, tales como la antitrombina, la proteína $\mathrm{C}$, el factor anti-hemofílico y la trombomodulina, entre otras.

Con la acción de este otro conjunto de proteínas, el sistema puede iniciarse y detenerse en el momento preciso. De lo contrario, su inicio y fin estarían descontrolados y sólo servirían para matar al animal. Así mismo, una vez formado, el coágulo debe ser disuelto más adelante para que sane la herida. Con este fin, otra proteína se activa, la plasmina, que se encuentra en forma inactiva (el plasminógeno). El mecanismo exacto para la activación de la plasmina a partir del plasminógeno no se conoce en detalle, aunque se sabe que requiere de otro conjunto complejo de proteínas para llevarse a cabo ${ }^{21}$.

Solamente si se ignora el proceso real y el funcionamiento complejo de la totalidad es cuando afirmaciones como «basta un conjunto de mutaciones que se acumulan y se mantienen a través de la selección natural para generar el sistema de coagulación más simple, que después se torna más complejo debido a otras mutaciones», tienen sentido. El misterio del sistema de coagulación no se encuentra en el número de proteínas involucradas en el proceso, sino en las interacciones y en el equilibrio que existe entre las funciones de cada una de ellas. No es el cómo surgió la materia del sistema, sino su organización lo que constituye un desafío para la ciencia.

En función de la interacción de las diversas proteínas, de la dinámica de cascada del sistema de coagulación y de la sintonía fina entre todos los elementos, cualquier ausencia en el sistema, lejos de ser una ventaja en menores proporciones, se convierte en algo letal. Es a esto a lo que Behe llama una

21 Elias, D. O. \& SouZA, M. H. L. (2005), «Antifibrinolíticos na profilaxia do sangramento pós-perfusão». Centro de Estudos Alfa. http://perfline.com/cear/artigos/aprotinina.html. 
complejidad irreducible, ya que según él no es posible pensar en un sistema de coagulación funcional que sea ventajoso si se retira una o más de las proteínas que actúan en la cascada. El sistema sólo funciona cuando todo está ensamblado. De igual forma, sistemas más simples deben ajustarse a esta característica.

Además del sistema de coagulación, Behe describe otros sistemas de enorme complejidad, organización y acción conjunta. La pregunta que él hace es: ¿Cómo es que este sistema puede haberse formado paso a paso gracias a pequeñas mutaciones aleatorias en el código genético, dirigidas por la selección natural, si su funcionalidad exige la acción de esas proteínas en conjunto? La probabilidad de una mutación conjunta al azar para generar un sistema complejo y funcional es prácticamente nula. Por lo tanto, a partir de estos datos, el darwinismo se encuentra realmente ante una ardua tarea. «Decir que la evolución darwinista no puede explicar todo en la naturaleza no equivale a decir que la evolución, las mutaciones aleatorias y la selección natural no ocurran. Éstas han sido observadas [...] en diversas ocasiones [...]. Estoy de acuerdo que la prueba confirma convincentemente la ascendencia común. Pero la pregunta fundamental permanece sin respuesta: ¿Qué es lo que impulsa a los sistemas complejos a formarse? Nunca se ha explicado de forma detallada, científica, cómo la mutación y la selección natural podrían construir las estructuras complejas, intrincadas, discutidas en este libro.» En base a sus reflexiones, Behe afirma categóricamente: «La evolución molecular no se basa en autoridades científicas. No hay publicación en la literatura científica [...] que describa cómo la evolución molecular de cualquier sistema bioquímico real, complejo, ocurre o pudo haber ocurrido. Hay afirmaciones de que tal evolución ocurre, pero ninguna de ellas con base en experimentos o cálculos apropiados. Ya que nadie conoce la evolución molecular por experiencia directa, y al no haber autoridad sobre la cual alegar ese conocimiento, podemos decir con certeza que [...] la afirmación de la existencia de la evolución molecular darwinista es simplemente una bazofia» ${ }^{22}$.

Una vez señaladas las deficiencias de la teoría hegemónica y hechas esas afirmaciones tan categóricas, es preciso analizar ahora cuáles son las respuestas presentadas por los defensores del darwinismo, que pudiesen librarlo de la acusación de ser un paradigma en crisis. Fue difícil seleccionar, dentro del debate en torno al libro de Behe, las cuestiones propiamente relacionadas a la ciencia. La mayoría de los artículos que se refieren a él simplemente sustentan un debate acalorado y apasionado entre creacionismo y evolucionismo.

22 BEHE, M. (1997a), p.179. 
Cuando una discusión toma este giro se anula toda posible confrontación fructífera de ideas, se cae en la trampa de etiquetar. El filósofo Arthur Schopenhauer cita esta práctica como una estrategia para vencer en un debate sin atenerse al contenido: «Una manera rápida de eliminar o, al menos de poner en duda una afirmación del adversario consiste en reducirla a una categoría generalmente detestable, aun cuando la relación sea poco precisa y tan solo de vaga semejanza. Por ejemplo: «eso es maniqueísmo», "es arianismo», «es pelagianismo» [...], etc. Así suponemos dos cosas: 1) que aquella afirmación es efectivamente idéntica a esa categoría, o al menos está comprendida en ella y estamos diciendo: "ah, jeso ya lo sabemos!»; y 2) que esta categoría ya está del todo refutada y no puede contener ninguna palabra verdadera ${ }^{23}$.

De hecho, al proponer Behe un diseñador inteligente, se aproxima mucho a las ideas creacionistas. Pero lo que debe cuestionarse en un debate digno de ser llamado científico son sus críticas al darwinismo, que en su caso se limitan a críticas científicas. Para reafirmar la capacidad del darwinismo, estas críticas deben ser rebatidas. Investigué, hasta donde me fue posible, las publicaciones de carácter científico que se refieren directamente a los cuestionamientos de Behe y el resultado fue sorprendente. El debate se limitó a consideraciones ideológicas, discusiones no racionales que se vuelven acusaciones y hasta la manipulación de datos científicos. Los pocos artículos que procuran tratar el problema a nivel científico repiten los problemas y las anomalías señaladas por Behe ${ }^{24}$.

La revista Boston Review, del Massachussets Institute of Technology (MIT), dedicó una parte de una edición a discutir los problemas propuestos por el libro de Michael Behe ${ }^{25}$. Allí, autores como Allen Orr, Russel Dolittle, Jerry Coyne, Richard Dawkins y Douglas Futuyma, intentan analizar las críticas contenidas en La caja negra de Darwin.

El artículo de Jerry Coyne se encuentra repleto de adjetivos, comenzando por el título: More crank science ${ }^{26}$. Coyne se refiere a los «académicos antievolu-

23 Schopenhauer, A. (1997), Como vencer um debate sem precisar ter razão, Rio de Janeiro, Topbooks, p. 174.

24 Cito en la bibliografía solamente las publicaciones que sirvieron de referencia directa a este artículo. El resultado completo de la búsqueda no se encuentra aqui, por el hecho de que muchos no traen cuestiones que exigirian um análisis más afinado. Hay también una cantidad enorme de documentos en Internet que tratan la cuestión como parte de la disputa simplista entre «creacionistas» $\mathrm{y}$ «evolucionistas». No he considerado estos documentos por que no considero que este sea un problema ideológico o teológico.

25 Vol. 22, n.1, feb/mar, 1997.

26 Crank, en el argot estadounidense, significa «excéntrico», «raro». 
cionistas» (colocando en esta categoría a todos los científicos no darwinistas) con el término peyorativo gadfly (persona irritante, desagradable) y dice que lo que Behe hace «no es ciencia», que el editor de su libro «buscó lucro y no exactitud», que Behe pretende ser un genio como Einstein y Newton, etc. Pero la respuesta de Coyne es un simple conjunto de afirmaciones sin fuentes científicas que las corroboren, las mismas afirmaciones que ya han sido negadas, más de una vez, con argumentos por Behe. Afirmar que los procesos metabólicos descritos por Behe pueden tener una explicación darwinista no es suficiente. Es preciso dar una explicación o al menos el lugar donde puede ser encontrada.

Cuando se refiere al concepto de complejidad irreducible de los sistemas bioquímicos, Coyne recurre a la teoría de Karl Popper sosteniendo que «la teoría de Behe sobre la complejidad bioquímica no es científica porque es infalsable: no hay observación o experimento que pueda refutarla». Lo curioso es que Popper afirmó eso mismo, pero con respecto al darwinismo ${ }^{27}$, aunque no niegue su valor para la ciencia: «He llegado a la conclusión de que el darwinismo no es una teoría cientifica susceptible de prueba, sino un programa de investigación metafísica - un posible sistema de referencia para teorías científicas comprobables [...El darwinismo] es metafisico por no ser susceptible de prueba. [...] Importa, así, demostrar que el darwinismo no es una teoría cientifica, sino metafísica $\rangle^{28}$.

Si Coyne aplicara el mismo criterio de cientificidad popperiano al darwinismo, ciertamente no lo usaría para rebatir la tesis de la complejidad irreducible. El mismo tono y la misma base de argumentación aparecen en una reseña de Coyne sobre el libro de Behe para la revista Nature. Siguiendo la estrategia descrita por Shopenhauer dice: «La meta de los creacionistas siempre fue el sustituir la enseñanza de la evolución por la narrativa proporcionada en los primeros once capitulos del Génesis. Cuando la justicia frustró sus esfuerzos, los creacionistas usaron una nueva estrategia: disfrazarse con el manto de la ciencia. [...] La alternativa científica de Behe a la evolución es, a fin de cuentas, una confusa e incomprobable miscelánea de ideas contradictorias» ${ }^{29}$.

Nótese aquí una sutileza que es en verdad una poderosa estrategia para derribar la tesis del adversario. No se puede afirmar si es el fruto de una confusión o de una deliberada malicia, pero la identificación de la evolución (afirmación factual ampliamente registrada) con la teoría darwinista de la evolución es una

27 Y el propio filósofo deja claro que cuando habla en darwinismo se refiere al neodarwinismo.

28 Popper, K. (1986), Autobiografia intelectual, São Paulo, Cultrix, p. 177, 180, 181.

29 COYNE J. A. (1996), "God in the details: the biochemical challenge to evolution», $\mathrm{Na}$ ture, 383, 227-228. 
acción recurrente - diversos científicos que he revisado acusan a Behe de negar la evolución y basan sus argumentos en esta acusación. En la cita anterior, Coyne habla de una «alternativa de Behe a la evolución» y no a la teoría darwinista. La verdad es que Behe no niega el «hecho» de la evolución (ver cita arriba), sino la explicación que la teoría darwinista hace de ella. Insistir que Behe niega un hecho y no un paradigma es una estratagema para ganar en el debate o de plano demuestra que existe un problema en la capacidad de interpretación y raciocinio de grandes figuras de la biología contemporánea.

Pero ¿cuál es la respuesta de Coyne a las críticas de Behe, en base a la teoría darwinista? Una es que, de hecho, las vías metabólicas descritas por Behe son «alarmantemente complejas» y que tal vez nosotros seamos «eternamente incapaces de imaginar» el camino de su evolución. Sin embargo, dice Coyne, el hecho de no podernos imaginar tal vía evolutiva no significa que ella no haya existido. «Nos enfrentamos no sólo a la carencia de datos, sino también al terrible hecho de que nosotros mismos somos criaturas evolucionadas con límites de cognición e imaginación.» Esta humildad en el reconocimiento de límites para explicar la evolución de sistemas complejos a partir del darwinismo tradicional, ¿no deberían existir también en sus críticas?, ¿en qué evidencias científicas basa Coyne la virulencia de su ataque? No presenta ninguna en los artículos aquí referidos ni hace referencia a publicaciones en las que podamos encontrarlas. Se trata simplemente de una reafirmación de la creencia en los principios de su paradigma.

No obstante, esgrimiendo argumentos de esta forma tan agresiva como débil, provee de armas hasta a los creacionistas, quienes también pueden decir: «el hecho de que no tenemos evidencias del Creador y de que no podemos explicar cómo fue que Él creó al mundo, no significa que no lo haya hecho». Como afirmación teológica o de fe, es perfectamente admisible, pero como ciencia es inadecuada.

El otro argumento de Coyne es decir que los sistemas complejos (como el sistema de coagulación sanguínea) no fueron evolucionando paso a paso, por la adición gradual de las proteínas que los componen. Las proteínas involucradas en estos sistemas podían actuar antes en otras funciones (por lo que fueron mantenidas) y después fueron «cooptadas» por ellos. Estas proteínas ya existentes formaron, de repente, un sistema integrado por numerosas proteínas que se desenvolvieron paralelamente cumpliendo otras funciones.

Este argumento fue también utilizado en otra publicación, por el biólogo David Ussery y el biotecnólogo Richard Thornhill ${ }^{30}$. De acuerdo a ellos, hay

30 ThORnhill, R. H. \& USSERY D. W. (2000), «A classification of possible routes of darwinian evolution», The Journal of Theoretical Biology, 203, 111-116 
cuatro caminos que llevan a una explicación darwinista de la evolución: 1) Evolución serial directa: ocurre por la acumulación de pequeños pasos; 2) Evolución paralela directa: modificaciones paralelas que ocurren en dos componentes que, juntos, adquieren una funcionalidad ventajosa; da como ejemplo la retina y la cavidad de los $\operatorname{ojos}^{31}$. 3) Eliminación de redundancia funcional: en este caso, cuando algunos elementos sufren una mutación y pasan a tener otra función, otros que eran parte del sistema pierden su utilidad, por lo que eliminarlos puede ser una ventaja para el sistema. El resultado final no puede ser entendido a partir de sus componentes actuales, sin la intervención de los componentes eliminados. En este caso, los pasos para la formación del sistema fueron «apagados». 4) Adopción de una función diferente: cuando las proteínas cumplían otras funciones $\mathrm{y}$, de repente, fueron cooptadas por otro conjunto de proteínas para constituir un nuevo sistema funcional.

Para Thornhill \& Ussery la complejidad irreducible es tan sólo una ilusión, resultado de los caminos 3 y 4 (Coyne hace referencia al 4). ¿Cuáles son los problemas de esas respuestas? ¿Ellas responden a los cuestionamientos de Behe y dan una explicación darwinista para la evolución de los sistemas complejos?.

En mi opinión, tales respuestas sólo son satisfactorias desde el punto de vista formal. Preservan la lógica del darwinismo al afirmar que es posible adecuar la complejidad constatada a la perspectiva darwinista. Sin embargo, una explicación científica requiere más que un esfuerzo formal para preservar una teoría. $\mathrm{La}$ «forma», en las ciencias naturales, debe ser cargada con «contenido» y es en este punto donde las explicaciones de arriba se vuelven insatisfactorias.

Es verdad que reconstruir todo el pasado evolutivo por la vía empírica directa es una tarea imposible y, en este caso, es preciso un esfuerzo imaginativo y especulativo. Pero no es sólo la biología evolutiva la que enfrenta este problema. La cosmología física también trata de la evolución del universo intentando reconstruir los pasos que precedieron, y formaron, el universo

31 Behe expone los problemas de esa explicación del ojo, mostrando la cantidad de moléculas involucradas en su funcionamiento, y concluye: «Ahora que la caja negra de la visión ha sido abierta, no es mas aceptable que una explicación evolutiva de esa capacidad tenga en cuenta sólo las estructuras anatômicas de ojos completos, como hizo Darwin en el siglo XIX (y como continúan haciendo hoy los divulgadores de la evolución). Todas las etapas y estructuras anatómicas que Darwin juzgó tan simples implican, en verdad, procesos biológicos inmensamente complicados que no pueden ser disfrazados por la retórica.» (BEHE, M. 1997a, p 25-32). Thornhill \& Ussery, incluso escribiendo cuatro años después de Behe han eludido sus críticas, simplemente ignoran sus argumentos y reafirmam la simplicidad de la evolución del ojo. 
actual, pasos que fueron apagados casi en su totalidad. Sin embargo, aunque la cosmología se caracterice por la especulación, su formalismo está sustentado en elementos reales, tales como las partículas elementales conocidas, átomos y moléculas, actuando en procesos resultantes de leyes conocidas y susceptibles de ser reproducidos por la imaginación científica.

Este, sin embargo, no es el caso de la explicación darwinista. El camino 3 tiene como único criterio la «imaginabilidad» y no la imaginación concreta. Es decir, tan sólo se supone un proceso posible, pero nadie lo reproduce, llenándolo con elementos posibles dentro de un cuadro científico imaginable y que preserve los principios fundamentales del darwinismo. Un artículo de Keith Robinson ${ }^{32}$ es citado por Thornhill \& Ussery para trazar un cuadro evolutivo darwinista probable de la formación del sistema de coagulación sanguínea. Pero Robinson describe un cuadro usando incógnitas como X y Y. Pero ¿qué sucedería al organismo que adquirió $X$, si $X$ fuese la fibrina (una proteína real y no una incógnita)? ¿O Y, si Y fuese la plasmina? Se puede suponer, como hizo Robinson, que las mutaciones en $X$ son neutras ipero la presencia de fibrina activa en la sangre no es algo neutro! ${ }^{33}$

En cuanto al camino 4, descrito anteriormente y mencionado por Coyne, se enfrenta a un problema relacionado con la probabilidad. Es posible, aunque difícil, imaginar la aparición (de una probabilidad bajísima) de sistemas complejos altamente funcionales y equilibrados tan sólo como el resultado de la interacción repentina y fortuita de decenas de moléculas que cumplían antes otras funciones. Pero, explicar así la formación de prácticamente todos los sistemas bioquímicos complejos es casi como admitir una intencionalidad oculta en la casualidad. La regularidad de un acontecimiento improbable debe indicar, en la ciencia, la existencia de un factor causante (una causa natural) y no una mera «coincidencia». Recurrir al factor tiempo no vuelve ese acontecimiento más probable. Aquí se está hablando de un sinnúmero de sistemas que componen al mundo vivo y no solamente de uno u otro órgano. Los ejemplos de cambio de funciones mencionados en el artículo de Thornhill \& Ussery extraídos del mundo macroscópico y se refieren a estructuras anatómicas ya formadas y a sistemas más simples con menos elementos. No es el caso de los sistemas bioquímicos complejos, que involucran decenas de proteínas en interacciones coordinadas, sincronizadas e interdependientes.

32 Robison, K. (1996), «Darwin's black box: irreducible complexity or irreproducible irreducibility?» www.talkorigins.org/faqs/behe/review.html.

33 Behe contesta estas y otras críticas en BEHE, M. (2000b), «In defense of the irreducibility of the blood clotting cascade: response to Russell Doolittle, Ken Miller and Keith Robison.» www.arn.org/docs/behe/mb_indefenseofbloodclottingcascade.htm.. 
En otro artículo, Ussery concuerda en que aún no hay una teoría satisfactoria que explique la complejidad bioquímica y afirma que este es un problema importante ${ }^{34}$. Al intentar explicar la formación de los sistemas que Behe llama irreduciblemente complejos utiliza palabras como «fácilmente puedo imaginar un escenario...»y va enlistando pasos virtuales en la formación del flagelo bacteriano sin hacer referencia, no obstante, a la selección natural y a la complejidad de ese órgano, explicada detalladamente por Behe ${ }^{35}$. Como ya afirmé, ese tipo de explicación serviría también para automóviles, aviones y computadoras. El darwinismo no es sólo una explicación de la sucesión gradual de las mutaciones, sino también de la perpetuación y direccionamiento de estos cambios por la selección natural.

Comentar otros artículos sobre este tema sería redundante, pero hay un episodio digno de narrarse y que puede ser un fuerte síntoma de la crisis de un paradigma. En el volumen mencionado de la Boston Review, el bioquímico Russel Doolittle también escribe un artículo criticando La caja negra de Darwin $^{36}$. Este artículo llama la atención porque cita una investigación publicada en la revista Cell, que derrumbaría el argumento de la complejidad irreducible de Behe. Según él, investigadores mostraron que la retirada de los genes que producen el plasminógeno en ratones provoca la trombosis, como era de esperarse. Posteriormente, retiraron de otros ratones el gen responsable de la síntesis del fibrinógeno y obtuvieron también el esperado resultado de complicaciones hemorrágicas. Más adelante cruzaron ambas razas de ratones $\mathrm{y}$, según Doolittle, la descendencia con deficiencia tanto de plasminógeno como de fibrinógeno era normal. La conclusión de Doolittle es que la investigación prueba que los argumentos de Behe en defensa de la complejidad irreducible habían sido derrumbados, pues dos de los elementos fundamentales del sistema fueron retirados y no sucedió nada.

Sorprendentemente, Doolittle cita equivocadamente las conclusiones de la investigación referida. En realidad, los autores dicen lo siguiente: «Ratones deficientes en plasminógeno y fibrinógeno son fenotípicamente indistinguibles de los ratones deficientes de fibrinógeno. Estos datos sugieren que la fundamental, y posiblemente única, función fisiológica esencial del plasminógeno es la fibrinólisis» ${ }^{37}$.

34 USSERY, D. (1997), «A biochemist's response to 'the biochemical challenge to evolution'». www.cbs.dtu.dk/staff/dave/Behe1.html.

35 BEHE, M. (1997a), p. 77-79.

36 Doolittle, R. F. (1997), «A delicate balance», Boston Review, 22, 28-29.

37 BugGe, T. H. et. al. (1996), «Loss of fibrinogen rescues mice from the pleiotropic effects of plasminogen deficiency», Cell, 87, 709-719. 
Es decir, lo que la investigación muestra realmente es que la descendencia deficiente en ambas proteínas referidas ¡no es normal! La conclusión de la investigación es que la ausencia de ambas provoca el mismo mal que la ausencia única del fibrinógeno. De igual manera, ninguno de los autores afirma (ni la investigación misma así lo indica) que las proteínas son dispensables, o que los ratones deficientes en ambas son normales.

Los motivos que impulsaron a un especialista como Doolittle a equivocarse de forma tan elemental y a citar erróneamente el resultado de una investigación como prueba de sus argumentos, no pueden ser identificados sin prejuicios. Pero no me parece que alegar la ignorancia o el engaño sea la primera hipótesis. Parece ser una prueba de la afirmación de Kuhn, de que el apego a un paradigma no se justifica racionalmente.

Un artículo de Niall Shanks y Karl H. Joplin presenta un análisis más equilibrado que indica los verdaderos problemas de Behe ${ }^{38}$. Ellos tocan una cuestión que considero realmente científica y filosófica: si es posible o no identificar una causa natural para la formación y evolución de los sistemas vivos complejos.

Conforme a lo que hemos visto, constatando la incapacidad de encontrar una explicación darwinista para la evolución de la vida en un nivel molecular, Behe concluyó la inviabilidad de una explicación natural para este fenómeno, recurriendo entonces a la figura de un diseñador inteligente. Su conclusión no es ciertamente una solución necesaria desde el punto de vista lógico.

Shanks y Joplin comentan: «El argumento central de Behe se concentra en afirmar que sistemas que satisfacen ciertas condiciones —sistemas constituidos por varios componentes claves, todos contribuyendo para la(s) función(es) final(es) del sistema como un todo y todos essenciales en la realización de estas funciones del sistema - no pueden ser originados por procesos no intencionales, naturales. Tales sistemas requieren un diseñador inteligente, sobrenatural. Consecuentemente, si pudiéramos formular una explicación naturalista plausible (sin recurrir a diseñadores de ningún tipo) para algunos sistemas que satisfagan los criterios de Behe, tendríamos motivos para cuestionar la validez general de su proposición.»

Los autores reflexionan, entonces, sobre la posibilidad de la ciencia de encontrar una explicación naturalista para la evolución de la complejidad bioquímica de los seres vivos. No obstante, sus reflexiones se basan en teorías

38 ShanKs, N. \& Joplin, K. H. (1999), «Redundant complexity: a critical analysis of intelligent design in biochemistry», Philosophy of Science, 66, 268-282. 
modernas de la complejidad, como la de Kauffman ${ }^{39}:$ «En resumen, la teoría de la complejidad predice, y los experimentos lo confirman, que los sistemas irreduciblemente complejos de Behe pueden resultar del fenómeno dinámico de la autoorganización. La autoorganización, que resulta de lo que Kauffman llama "order for free», puede ser explorada en provecho de la evolución de sistemas biológicos» ${ }^{40}$.

Sin embargo, Kauffman no puede ser incluido entre los defensores de la ortodoxia darwinista. Su teoría de la complejidad no puede ser simplemente «incorporada» a la teoría sintética sin perjuicio de sus principios, hecho que lo llevó a sugerir: "hace falta repensar la teoría evolutiva [...]. Necesitamos ver la vida de una manera nueva e interpretar nuevas leyes para su desdoblamiento» ${ }^{41}$.

Aun cuando tocan la cuestión central del problema planteado por Behe, Shanks y Joplin no osaron reconocer, en el artículo referido, la insuficiencia del darwinismo para responder al «desafío de la bioquímica». Queda claro que la búsqueda de una explicación naturalista de la evolución, de cara a los nuevos descubrimientos de las ciencias biológicas, debe ser realizada a partir de teorías alternativas fuera de la ortodoxia darwinista hegemónica. Este parece ser el punto central del debate en una filosofía de las ciencias biológicas.

La propuesta de Behe no puede ser aceptada por la ciencia por razones metodológicas y de límite de alcance. Pero la pregunta sigue en el aire: si no es obra de un diseñador inteligente actuando directamente en el mundo, ¿cómo se originan, mantienen y evolucionan los sistemas vivos, caracterizados por estructuras extremadamente complejas que no se someten a las explicaciones del darwinismo? Tal vez sea ese el verdadero desafío para quien quiera hacer ciencia en la actualidad.

\subsection{La Crítica de Margulis}

Lynn Margulis observó la insuficiencia y lo inadecuado de los principios neodarwinistas cuando se aplican a la vida en su nivel microbiológico. Además, comprendió que, al no aplicarse al mundo vivo elemental, esos princi-

39 Cf. Kauffman, S. A. (1997), «O que é vida?» Schrödinger estava certo? In: MuRPHY, M. P., O’NEILl, L. A. J. (1997) «O que é vida?» 50 anos depois: especulações sobre o futuro da biologia, São Paulo, Edunesp. p. 101-135.

40 SHANKS, N. \& JOPLIN, K.H. (1999).

41 Kauffman, S.A. (1997), p. 132-133. 
pios no pueden ser aplicados a la vida de un modo general, a su origen y a la evolución de las especies. Su cometario crítico a los neodarwinistas está en función de aquello que ya comenté anteriormente: nuevos campos de investigación revelaron realidades que no concuerdan con la explicación hegemónica, en función de su complejidad y organización. «Genetistas, ecologistas, microbiólogos, fisiólogos y otros moradores del laboratorio, así como experimentadores, tienden a evitar discutir sobre las implicaciones de su trabajo en la teoría evolutiva. La mayoría de ellos simplemente no tiene idea de cómo la complejidad de la vida evolucionó o de plano no escriben acerca de ello» ${ }^{42}$.

Para Margulis, los principios consagrados del darwinismo actual sirven, cuando mucho, para describir mutaciones intra-especies y para ser aplicados a los mamíferos. Éstos, por cierto, junto con otras clases de animales y plantas macroscópicas, eran los principales seres vivos conocidos por la Biología hasta cierto momento de la historia. No es de sorprenderse que la teoría dominante se adecuara a ellos. «En lugar de los formalismos idealizados de la «sintesis moderna» darwinista, los principios organizados para el entendimiento de la vida requieren un nuevo conocimiento de química y metabolismo. Descubrimientos en el interior del funcionamiento de las células esclarecen el modo de evolución, desde que Darwin y sus seguidores inmediatos escribieran sus análisis. Los resultados de la nueva ciencia de laboratorio y del campo contradicen, ignoran o marginan el formalismo del neodarwinismo, excepto para variaciones dentro de poblaciones de mamíferos y otros organismos que se reproducen sexualmente» ${ }^{43}$.

La reflexión de Margulis tiene el siguiente raciocinio. El paso principal que hizo posible la complejidad actual y la variedad de la vida fue la aparición del núcleo celular, evento que ella denomina «eukaryosis». Los siguientes pasos, también fundamentales pero exclusivos de las eucariotas, fueron la reproducción sexual, la incorporación de organelos — como las mitocondrias y los cloroplastos - y la adquisición de los órganos de locomoción de algunas células, los cilios. Éstas fueron adquisiciones posteriores en una tierra habitada exclusivamente por bacterias durante cerca de dos mil millones de años. Esos pasos fueron decisivos en la formación de los variados organismos que constituyen los otros cuatro reinos en los que se divide la vida ${ }^{44}$. El argumen-

42 Margulis, L \& SAGAN, D. (2002a), p. 37.

43 Margulis, L \& SAgAN, D. (2002a), p. 38-39.

44 Los cinco reinos, según Margulis, son Monera (que incluye todos los tipos de bacterias y algas verdeazuladas - que son procariotas), Protoctista (que incluye los seres unicelulares eucariotas y los pequeños multicelulares), Fungi (todas las especies de hongos), Plantae (plantas) y Animalia (animales). 
to de Margulis dice que tales pasos no pueden ser explicados por mutaciones aleatorias. Sus investigaciones revelan que diversos orgánulos son fruto de un proceso de simbiosis: bacterias que se juntaron, intercambiaron sus genes $\mathrm{y}$, sacando provecho de esta integración, acabaron fundidas definitivamente. Según ella, la propia «eukaryosis» fue el resultado de una combinación simbiogenética. Esta fusión de genomas o la adquisición de conjuntos completos de genes por un organismo, y no las mutaciones aleatorias en el ADN, son los eventos que pueden explicar el surgimiento de nuevas especies.

La conclusión a la que llega Margulis afecta dos ejes básicos del darwinismo y algunas conclusiones derivadas de ellos. Las grandes mutaciones responsables de la evolución no son fruto de variaciones casuales que se acumulan en los organismos: "La visión común es que la vida evoluciona a través de la mutación genética aleatoria, la cual, además, es con frecuencia perjudical. . Las mutaciones al azar, ciegas y sin dirección, son enaltecidas como la principal fuente de novedad evolutiva. Nosotros (y un contingente cada vez mayor de estudiosos de la vida con una orientación semejante) no estamos totalmente de acuerdo. Enormes lagunas en la evolución fueron saltadas por la incorporación simbiótica de componentes previamente perfeccionados -componentes labrados en linajes separados. La evolución no empieza desde cero cada vez que surge una nueva forma de vida» ${ }^{45}$.

Esta afirmación también pone en riesgo algunas consecuencias de los ejes darwinistas, como el gradualismo de las mutaciones y la lucha por la supervivencia. Para Margulis, la fuerza evolutiva central es la simbiosis, que proporciona grandes saltos en la evolución a través de la herencia de genomas adquiridos, y no las mutaciones graduales de la teoría darwinista dominante. Además, la idea de una naturaleza exclusivamente competitiva también es relativa, según observa la propia bióloga: «[...] La fusión de la reproducción vegetal con la sensibilidad y el gusto de los animales es una demostración de los considerables poderes de la sinergia y la convergencia de la vida. Los seres vivos no sólo compiten y luchan, sino también se asocian y trabajan en conjunto» ${ }^{46}$.

Sin embargo, Margulis afirma no rechazar el darwinismo, sino el neodarwinismo. Por ejemplo, no rechaza el papel de la selección natural, principio que considera lo único central y adecuado de la teoría de Darwin. Para ella el núcleo central de la teoría de Darwin que posee validez incuestionable es el papel de la selección natural, por eso se reivindica «darwinista y no neodar-

45 Margulis, L. \& Sagan, D (2002b), O que é vida?, Rio de Janeiro, Jorge Zahar, p. 23.

46 Margulis, L. \& SAGAN, D. (2002b), p.23. 
winista» (este es el título del primer capítulo de Acquiring genomes). Pero si consideramos que el darwinismo sólo se establece como paradigma hegemónico a partir de la síntesis moderna, sus cuestionamientos no dejan de representar una crítica al paradigma dominante. Además, aunque reconoce el papel de la selección natural, la proposición de Margulis parece darle tan sólo un papel obvio: el de preservar los organismos que están bien acoplados con su entorno. Eso me parece el simple reconocimiento de una evidencia trivial: si el mantenimiento de un organismo vivo depende del equilibrio de su estructura interna con el medio que lo rodea, sólo se mantendrán aquellos que tengan una relación equilibrada, pereciendo todos los demás que, por algún motivo, no consiguen alcanzar ese equilibrio. La selección natural pierde entonces su lugar de concepto teórico que explica el mecanismo de la evolución y que es responsable de la complejidad de los seres vivos y del cambio de las especies. Por lo tanto, en un análisis más preciso, la visión de Margulis atañe no sólo al neodarwinismo, sino al darwinismo en sí mismo, aunque ella, por razones no evidentes, no admita tal conclusión.

En la visión hegemónica del darwinismo, el ADN es visto como el «programa» en el cual está inscrita toda la información acerca del desarrollo de un organismo y los genes son considerados las unidades mínimas de información de ese programa. Las pequeñas mutaciones en la disposición de las bases que constituyen los genes, conservadas por la selección natural y que se acumulan con el tiempo, serían las responsables de la evolución. Margulis y otros autores rechazan esta interpretación, sin todavía (y obviamente) negar el papel central del ADN en el almacenamiento de la información sobre la constitución de los organismos vivos. Eric D. Schneider y James J. Kay, por ejemplo, atribuyen a los genes el papel de almacenamiento de las informaciónes útiles generadas por el proceso de autoorganización y no el de mecanismo generador del desarrollo y la variedad de la vida: "[Los genes] son el registro de la autoorganización exitosa. Los genes no son el mecanismo de desarrollo; la autoorganización es el mecanismo [...] (El papel del gen es) actuar como un banco de datos de información para estrategias de autoorganización que funcionan» ${ }^{47}$.

Tal noción es compartida por Margulis y Sagan cuando afirman que «la molécula de ADN, tal como discos de computadora, almacena informaciones evolutivas pero no las crea $»^{48}$. Mutaciones aleatorias en el ADN, o inducidas

47 SCHNEIDER, E. D. \& KAY, J. J. (1997), Ordem a partir da desordem: a termodinâmica da complexidade biológica. In: MurPhY, M. P. \& O’NEILL, L. A. J. (1997), p. 198.

48 Margulis, L. \& Sagan, D. (2002a), p. XVI. Henri Atlan también propone la revisión de la concepción del ADN como programa y sugiere su comprensión como «datos almacena- 
artificialmente en el laboratorio, son generalmente nocivas. De hecho, ejercen un papel pequeño en la saga evolutiva pero son incapaces de explicar el proceso evolutivo como un todo.

Hasta ahora se ha hablado de la evolución de las especies. Pero ¿y en cuanto al origen de la vida? En este aspecto, Margulis también sustenta una visión distinta de los neodarwinistas, aunque no sea la autora de esa concepción. Ella imagina la organización de la vida como una respuesta a los gradientes de temperatura entre la tierra y el espacio circundante, siguiendo el rumbo de las proposiciones de Schneider y Kay, que interpretan la vida a partir de las leyes de la termodinámica y de las estructuras disipativas de Ilya Prigogine ${ }^{49}$. Eso significa que la vida no es un acontecimiento casual, accidental, improbable y sin propósito, sino un comportamiento esperado de la naturaleza a partir de las leyes conocidas de la termodinámica. Es decir, la estructura organizada de la vida tiene un «propósito», tal como el de los tornados o de los patrones organizados que emergen en la experiencia de las «células de Bénard», que son estructuras organizadas que aceleran la reducción de gradientes de temperatura.

Además, Margulis comparte con los biólogos chilenos Humberto Maturana y Francisco Varela la noción de «autopoiesis», que aplicada al origen de la célula excluye totalmente el corpus darwinista como explicación posible, aunque también mantiene el papel de la selección natural según su explicación respecto a la evolución (un papel cuestionable, como ya se observó). Para Maturana y Varela, una célula puede ser descrita, en su complejidad y funcionamiento, como una «máquina autopoiética», entendiendo con esto un sistema autónomo que tiene como finalidad constante el producirse a sí mismo. Ellos explican la evolución como un proceso de «acoplamiento estructural» de un sistema autopoiético a las condiciones del ambiente, donde los organismos procuran perpetuar su autopoiesis adaptando su estructura al medio en el que viven. En este sentido, los que consiguen mantener un acoplamiento estructural dentro de las mutaciones del ambiente son los aptos para permanecer vivos. Para Maturana y Varela, no existe la supervivencia del «más apto», sino simplemente la «supervivencia del apto» ${ }^{50}$. La «competen-

dos» interpretados por el conjunto complejo constituído por la red de reacciones metabólicas del organismo - algo así como una especie de «programa» distribuído por el cuerpo vivo. Cf. ATLAN, H. (2002), «DNA: programa ou dados?» In: MoRIN, E. (2002), p. 157-171.

49 Margulis, L. \& Sagan, D. (2002a), p.42-50; Schneider, E. D. \& Kay, J. J. (1997), p. $187-201$.

50 Maturana, H. \& Varela, F (2001), A árvore do conhecimento: as bases biológicas da compreensão humana, São Paulo, Palas Athena. 
cia» por la supervivencia no forma parte de la naturaleza, sino de la descripción del observador. Los autores no niegan la selección darwinista y afirman que el papel atribuido por Darwin a la selección natural debe ser entendido como una metáfora para el acoplamiento estructural. Hay, en este caso, un cambio de enfoque del proceso evolutivo: de la selección natural como agente al propio organismo que tiende a estructurarse para mantener su autopoiesis ${ }^{51}$. De cualquier forma, cabe aquí el mismo cuestionamiento sobre el papel desempeñado por la selección natural como motor de la evolución, junto con las mutaciones aleatorias del ADN, ejes esenciales del neodarwinismo. El acoplamiento estructural no son mutaciones lentas al azar y la sintonía con el medio es tan sólo una obviedad y no un principio que puede generar la evolución.

Ya para el origen de los sistemas autopoiéticos, el darwinismo está completamente excluido. La selección natural sólo puede ser aplicada a organismos complejos «ya existentes». Aunque los autores no expresen un rechazo por el darwinismo, queda implícito cuando uno de ellos afirma: «La constitución de la identidad de un individuo antecede, empírica y lógicamente, al proceso de evolución» ${ }^{52}$. O más claramente: «El establecimiento de un sistema autopoiético no puede ser un proceso gradual: el sistema autopoiético o existe o no existe. De hecho, su establecimiento no puede ser un proceso gradual porque un sistema autopoiético es definido como sistema [...] debido a su organización. Por lo tanto, una unidad topológica o se encuentra conformada por su organización autopoiética y el sistema autopoiético existe y permanece, o no hay unidad topológica o está formada de diferente forma y no existe un sistema autopoiético [...]. En consecuencia, no hay y no puede haber sistemas intermedios $»^{53}$.

Es decir, para que surja la complejidad del sistema vivo a nivel celular (una complejidad formada por la interacción bioquímica de moléculas específicas) el darwinismo no ofrece una respuesta, dado que esta complejidad no puede surgir gradualmente ni por pequeñas modificaciones sostenidas por la selección natural.

Las proposiciones de Margulis refuerzan la idea de que el paradigma neodarwinista llegó a su límite de productividad y las anomalías se están volviendo intolerables para el avance de la comprensión de la vida. Si bien Mar-

51 Según Maturana y Varela, el valor de la naturaleza en cuanto agente seleccionador, que aparentemente dirige los cambios en los organismos, fue una interpretación posterior equivocada de la selección natural. Cf. Maturana, H. \& VARELA, F. (2001), p. 113.

52 Varela, F. in: Maturana, H. \& VArela, F. (1997), De máquinas e seres vivos: autopoiese - a organização do vivo, Porto Alegre, Artes Médicas, p. 47.

53 Maturana, H. \& Varela, F. (1997), p. 88. 
gulis dice que conserva el darwinismo original en sus reflexiones, es difícil percibir qué papel puede tener en el cuadro general de una teoría de la evolución a partir de sus proposiciones.

Existe la necesidad, como se puede observar, de una nueva interpretación de la evolución que se contraponga al determinismo genético del darwinismo moderno, ya que los conocimientos de la biología se están ampliando y separando de las posibles explicaciones de la visión dominante. El «darwinismo» de Margulis, según ella, no es el de los neodarwinistas. Pero, en mi opinión, tampoco es el de Darwin. Éste queda completamente desfigurado cuando la selección natural (único concepto sobreviviente) pierde su fuerza como explicación de la evolución y es mantenida como un accesorio. Si no existe el «más apto» y la competencia ocurre tanto como la simbiosis y la cooperación, ¿qué «selecciona» la naturaleza? Ya que no se trata de la supervivencia de los «más aptos», ni del resultado de una lucha para sobrevivir, sólo resta la afirmación de la «supervivencia de los que sobreviven», de los que no son defectuosos, de los que no tienen problemas en su relación con el medio ¿Sería eso capaz de generar evolución?

\subsection{Crítica de Máximo Sandín}

Mientras que Lynn Margulis se rehúsa a abandonar el rótulo de darwinista (incluso cuando las consecuencias de sus reflexiones conduzcan a una posición distante del núcleo del darwinismo) y Michael Behe propone una alternativa no naturalista a la teoría de la evolución de Darwin, Máximo Sandín rechaza vehementemente la teoría darwinista en cualquiera de sus versiones, y al mismo tiempo propone una explicación naturalista alternativa para el fenómeno de la evolución, sin recurrir a principios sobrenaturales.

Lo que caracteriza su trabajo es la abundancia de datos científicos y referencias a investigaciones diversas que, en su opinión, serían suficientes para que el darwinismo fuese completamente abandonado. No obstante, el apego ciego al paradigma hegemónico impide que los biólogos perciban o admitan lo inadecuado de los datos más recientes de la ciencia a la teoría sintética. El resultado es la pérdida de la base científica, factual, de la biología, sacrificada en nombre de la conservación de la teoría dominante. Si por un lado, conforme a lo anteriormente descrito, las tentativas de salvar al darwinismo han demostrado ser más retóricas y formales que científicas y factuales, en función de la ausencia de datos o el respaldo de investigaciones reales que les proporcionen más contenido, Sandín hace reaparecer el aspecto científico del 
estudio sobre la evolución cuando ampara su proposición con incontables datos (imposibles de ser reproducidos aquí) y presenta una alternativa compleja para un problema complejo.

La primera y más básica comprobación de Sandín es que la vida es un fenómeno de la más alta complejidad. Eso no significa simplemente reconocer las intrincadas relaciones entre los numerosos elementos que componen a los organismos vivos, sino el hecho de que sólo se puede hablar de vida, en su forma más elemental, cuando todos estos elementos ya están en una interacción coordinada y produciendo la funcionalidad del sistema. No se trata de reconocer la vida como algo «complicado», sino como un fenómeno complejo (en el sentido referido en el primer inciso de este artículo). Es lo mismo que cuando Behe habla de enunciar el concepto de complejidad irreducible.

La complejidad implicada en el funcionamiento de la vida, hasta en las aparentemente más simples funciones como la codificación de una proteína por un gen, choca con la simplicidad de las mutaciones lentas, graduales y al azar del darwinismo. A ningún científico que conozca el funcionamiento de la célula, las relaciones bioquímicas entre las moléculas de la vida y el enorme equilibrio entre las funciones celulares deja de impresionarse con la intrincada cadena de relaciones que hacen que la vida exista. Sandín ve en esto una contradicción entre los datos reales y la teoría que actualmente los intenta explicar.

Los estudios avanzados de genética y los sorprendentes descubrimientos en el estudio del genoma de diversos seres vivos han ido revelando que el funcionamiento de los procesos biológicos involucra mucho más factores que una simple relación mecánica gen-proteína o genotipo-fenotipo, que caracterizan el concepto tradicional defendido por muchos biólogos. «En efecto, cada vez son más los mecanismos y procesos biológicos que tienen difícil encuadre dentro de la Teoría Sintética. Los elementos móviles, las secuencias repetidas, los genes homeóticos, las secuencias reguladoras, ... Todo esto, sometido, a nivel celular, a un complejísimo control de proteínas que «revisan» y «reparan» los errores de duplicación, que controlan el correcto funcionamiento celular y que se autorregulan entre sí. A nivel de desarrollo embrionario, por campos morfogenéticos que controlan con increíble precisión el proceso espacial y temporal de la formación de tejidos y órganos y que son capaces de corregir accidentes y reconducir el proceso. Y a nivel orgánico, por sistemas neuro-endocrinos de regulación que relacionan tejidos y órganos entre sí, bajo la protección de un complejo sistema inmunitario con una sorprendente capacidad de respuesta a agentes extraños.La gran precisión con que funciona cada uno de estos mecanismos y la estrecha interconexión entre todos ellos, es decir, su calidad de sistemas complejos, cuyos elementos 
no pueden actuar como partes independientes, concede poco margen de actuación a los errores aleatorios como mecanismo de evolución. Pero si además tenemos en cuenta su capacidad de autorreparación, tanto a nivel celular como embriológico ¿qué campo de acción le queda a la Selección Natural para los cambios en los organismos que impliquen realmente evolución?» ${ }^{54}$

Sandín enfrenta el desafío de interpretar esta gran cantidad de datos proponiendo una alternativa teórica completamente heterodoxa. Una de las sorpresas del genoma humano es la verificación de que gran parte de sus genes es de origen bacteriano (como ya lo constató Margulis). Conjuntos enteros de genes bacterianos se fundieron y dejaron sus secuencias (con pequeñas modificaciones) en el ADN humano (y de otros animales y plantas). La otra sorpresa es que una parte tiene un origen viral. Varias secuencias con funciones importantísimas en el desenvolvimiento humano se derivan de virus. De acuerdo con datos recientes citados por Sandín ${ }^{55}$, en el genoma del ser humano la parte codificadora de proteínas corresponde al 1.5\%, aproximadamente, de la totalidad del ADN. De este porcentaje, la fracción que no se deriva de genes bacterianos está constituida por virus endógenos (virus que se implantaron en el ADN y permanecen en él), que representan más del $10 \%$, elementos móviles (partes que se separan de la molécula del ADN y se insertan en otro lugar de la misma molécula), que representan cerca del $45 \%$ y secuencias repetidas. Sandín afirma que los elementos móviles y las secuencias repetidas también tienen origen viral.

Asimismo, la parte no codificadora del genoma, que representa el 98.5\% del total, demuestra tener una función reguladora y no puede ser interpretada ya como ADN «basura». Aislados del «contexto» del ADN (con secuencias codificadoras y no codificadoras), los genes no cumplen la misma función que cuando se encuentran insertados en la totalidad. Esto significa que el llamado ADN «basura» o «egoísta» es un componente de la totalidad y que cada gen en particular sólo ejerce su función cuando está insertado en esta totalidad autorreguladora. El genoma es un caso de totalidad en el que la función específica de cada parte no informa sobre el funcionamiento del todo. Es un sistema complejo cuyas partes sólo pueden ser entendidas en función del todo.

54 SANDín, M. (1997), «Teoría sintética: crisis y revolución», Arbor, 623/624, 269-303.

55 Hay una amplia referencia bibliográfica acompañando principalmente a su último artículo que remite a los mas recientes descubrimientos del estudio del genoma humano. Cf. Cf. SANDín, M. (2005) «La transformación de la evolución», Boletín de la Real Sociedad Española de Historia Natural, 100, 139-167. Quienes deseen obtener más datos y referencias pueden recurrir al sitio del autor en: www.uam.es/personal_pdi/ciencias/msandin 
Este porcentaje importante, el $98.5 \%$ del ADN, «responsable del control de la expresión de los genes codificadores de proteinas y de la regulación en general, es decir, el que ejerce la función fundamental en la evolución [...] está constituido por secuencias altamente repetidas como las SINE (short interpersed elements) entre ellas, las $A L U$ (elementos repetidos especificos de primates), las LINE (long interpersed elements), intrones y elementos ultraconservados, así como un notable número de virus endógenos» ${ }^{56}$.

Sandín niega la interpretación de que esta conformación del genoma pudo haber sido resultado de la mutación aleatoria y la selección natural. También rechaza la explicación de Dawkins que atribuye a los genes un comportamiento egoísta, que justificaría la presencia de la parte no codificadora del ADN. Para él, la hipótesis más razonable sería que los virus se insertaron (por su capacidad de «infección») en genomas más simples y transformaron los resultados de la relación genotipo-fenotipo. Es decir, un determinado conjunto de genes, responsable de ciertos organismos con una determinada configuración, fue modificado por la inserción de nuevas secuencias provenientes de virus que lograron implantarse en las células germinales o por la activación de genes a partir de la presión del medio, lo que generó un organismo nuevo, diferente del anterior. «La diferencia fundamental entre ambas explicaciones es que la primera [derivada del concepto del ADN egoísta] se basa en una «hipótesis» que atribuye a la molécula de ADN unas capacidades omnipotentes y una condición moralmente «despreciable» ya descalificadas por los datos reales, mientras que la segunda no parte de preconceptos y si de un hecho comprobado: La capacidad de los virus para integrarse en los genomas» ${ }^{57}$.

Por lo tanto, para Sandín, el mecanismo fundamental de la evolución no es la mutación aleatoria ni la selección natural, sino la integración de virus en genomas ya existentes. En retroceso hacia el origen del proceso, llegamos hasta las bacterias, primera forma de vida en el planeta.

De acuerdo con las referencias de Sandín, las investigaciones de Radhey Gupta y William Ford Doolittle revelan que el conjunto de genes responsables de la transmisión de información genética y del metabolismo en las eucariontes tienen su origen en los organismos procariontes: arqueobacterias y eubacterias. Estos datos fueron obtenidos a través del secuenciamiento genético y la comparación de eucariontes y procariontes. Sandín observa que estas investigaciones muestran, por un lado, una extremada conservación de las funciones celulares básicas, hecho que revela una resistencia a las mutaciones al

56 SANDÍN, M. (2005).

57 SANDÍN, M. (2005). 
azar y, por otro, que las funciones celulares básicas de los organismos multicelulares no fueron resultado de mutaciones aleatorias. Doolittle afirma que las otras funciones celulares no tienen un origen conocido, pero que debió existir algún dominio de organismos capaces de transmitir sus genes horizontalmente (como hacen las bacterias), hoy en día extintos, que transmitieron al núcleo de las eucariontes los genes responsables de esas funciones. Sandín propone que en realidad no se trata de un otro dominio de seres vivos, sino que los responsables de la inserción de los genes que responden a las otras funciones celulares fueron los virus. "Actualmente, sabemos que existe en la Naturaleza algo que no es exactamente un cuarto dominio de seres vivos, que no se ha extinguido, pero que tiene la capacidad de «transferencia horizontal de genes»: Los virus» $\rangle^{58}$.

Hoy se sabe que los virus actúan introduciendo su material genético en una célula y haciendo copias de sí mismos. Esas copias invaden otras células y en algunos casos llegan a producir un efecto dañino en todo el organismo. Este es el aspecto patológico más conocido de los virus. Sin embargo, los virus también se insertan en lugares específicos del genoma del anfitrión y allí permanecen, inactivos o produciendo sus propias proteínas. Los retrovirus entran en la célula y, para poder insertarse en el ADN del huésped, crean una copia ADN de sí mismo (a través de la transcriptasa inversa) y esta copia se implanta en el genoma. Como en este proceso de transcripción no existe un mecanismo de corrección de errores de duplicación ( como hay en la duplicación celular), las copias insertadas contienen frecuentes mutaciones en relación al molde original (el retrovirus).

Las secuencias virales insertadas que no tienen actividad alguna pueden ser activadas por factores externos de inducción de actividades recientemente conocidos : carencia o exceso de nutrientes, radiaciones y sustancias químicas ajenas a la célula. Una vez activadas, se separan de la zona en la que se insertaron, reconstituyen su cápsida y recuperan su capacidad de infección. Secuencias de origen viral también pueden moverse en la molécula del ADN o insertar copias de sí mismas en otras regiones del genoma (algunas son regiones «preferenciales», lo que muestra que no es un proceso realmente aleatorio). El resultado de esta característica de insertar copias de sí mismo son las secuencias repetidas encontradas en los genomas, algunas con funciones vitales para el organismo, tales como el control del desarrollo embrionario y el funcionamiento de órganos importantes ${ }^{59}$.

58 SANDín, M. (2004), «Sucesos excepcionales en la evolución». www.uam.es/personal_pdi/ ciencias/msandin.

59 SANDín, M. (1997). 
Estas características de los virus los hacen responsables de la inserción de nuevas secuencias con contenido informativo en el genoma, así como de la reorganización de genomas ya existentes. Si el material genético implantado por los virus fuera tan sólo un agregado insustancial al genoma, o si la reorganización provocada por su movilidad, duplicación e inserción no estuviese involucrada en funciones vitales, el fenómeno no tendría importancia considerable en el estudio de la evolución. Sin embargo, la presencia masiva de secuencias virales en el ADN de animales y plantas, su función reguladora (dentro de una totalidad compleja) y sus funciones específicas en el desarrollo embrionario y en características importantes de los organismos, hacen que Sandín les atribuya no sólo una gran importancia en la evolución de la vida sino un papel determinante.

El interés por el secuenciamiento de genomas en los últimos años reveló que secuencias de origen viral están involucradas de forma concluyente en el surgimiento de la placenta en los mamíferos, se expresan como parte constituyente en el cerebro, pulmones y otros tejidos y órganos, en la morfogénesis, en la codificación de proteínas esenciales para los organismos eucariontes (inclusive el ser humano) y en el sistema inmunológico, entre otros ${ }^{60}$.

Otro factor comprobado por numerosas experiencias y observaciones es la influencia que el medio tiene sobre el ser vivo, tanto en la adaptación a su entorno como en su organización estructural. No se trata simplemente de respuestas fenotípicas, sino de transformaciones en el funcionamiento mismo de la estructura genética que resultan de las presiones del medio. En opinión de Sandín, las complejas adaptaciones fisiológicas y anatómicas que se observan en la naturaleza no fueron producto de mutaciones aleatorias en un solo individuo, sino de la capacidad de comunicación entre el organismo y el medio. Henri Atlan menciona que la ciencia tiene ejemplos documentados de respuestas del ADN a las condiciones del medio (sin mutación en su estructura) que son hereditarias. Es decir, el ambiente produce modificaciones en el contexto de la célula que, a su vez, inducen a respuestas diferentes del genoma. Como resultado se obtienen manifestaciones fenotípicas diferentes a partir de un mismo genoma, que dependen de las condiciones del medio. De acuerdo con Atlan, algunas de estas respuestas del ADN son suficientemente estables como para ser transmitidas a los descendientes. Así, concluye que el ADN no es un «programa» genético, sino un conjunto de «datos» interpretados por la totalidad de la célula en su relación con el ambiente a través del metabolismo ${ }^{61}$.

60 SANDíN, M. (1997; 2005).

61 AtLAN, H. (2002), «DNA: programa ou dados?» In: MoRIN, E. (2002), p. 157-171. 
Sandín también menciona elementos que indican la importancia de esta interacción con el medio en la configuración de los organismos. Uno de los ejemplos que se puede citar aqui es el splicing alternativo. Ciertos estudios han comprobado que las diferentes copias del ARN resultantes de un mismo gen ( $\mathrm{y}$ su consecuente producción de proteínas diferentes a partir de una misma secuencia genética) no son frutos de una combinación al azar de exones, sino que comprenden un conjunto de acciones coordenadas, determinadas por el ambiente donde la célula está insertada ${ }^{62}$. Esto es muy diferente de la selección darwinista, según la cual el medio sólo actúa sobre algo ya disponible a través de mutaciones al azar, pero que no produce mutaciones como resultado de una interacción.

A partir de esto y de numerosos datos documentados por los medios científicos reconocidos, Sandín afirma que existen dos tipos de fenómenos involucrados en el cambio y diferenciación de los seres vivos: la adaptación y la evolución. La adaptación es un ajuste del organismo vivo a su entorno, sin modificaciones cualitativas en la estructura que lo caracteriza. Evolución se refiere a una modificación cualitativa en la propia organización estructural de ese organismo.

Según él, los descubrimientos recientes sobre la interacción entre el organismo y su medio conducen a la propuesta de que la adaptación es un fenómeno de tipo lamarckiano. El medio, no las mutaciones al azar, provoca que determinados grupos de seres vivos asuman ciertas características. Pero estas adaptaciones no conducen a modificaciones de organización (evolución) al no generar cambios genéticos sino respuestas diferentes a las presiones ambientales. "En cuanto a los ajustes a diferentes condiciones ambientales (un fenómeno diferente a los cambios de organización), los sistemas de control y regulación de la información genética han mostrado una variada gama de mecanismos de respuesta al ambiente, tanto epigenéticos: metilación, imprinting, ARN de interferencia, silenciamiento transgénico (Mattick y Gagen, 2001; Elgin y Grewal, 2003; True et a., 2004)... como genéticos: splicing alternativo, retrogenes y retropseudogenes (Vitali, p. et al., 2003), transposiciones e inserciones de elementos móviles (Schramke y Allshire, 2003). Incluso el desarrollo embrionario responde de una forma constatada a las condiciones ambientales (Rutherford y Lindquist, 1998; Hall, 2003)» ${ }^{63}$.

La diferencia entre adaptación y evolución cuestiona la tesis darwinista de que las diferencias entre los organismos son mutaciones en el código genéti-

62 SANDíN, M. (2005).
63 SANDÍN, M. (2005). 
co, que de ser ventajosas serían seleccionadas por la naturaleza - mutaciones que se acumularían hasta el surgimiento de una nueva especie. Sandín (como Maturana y Varela) niega el concepto de que un organismo puede ser clasificado como «más apto» que otro y que esta mayor adaptación sea la razón de la evolución. "Y con esto hemos llegado al concepto estelar de la doctrina prevalente: el término «más apto» (o, en su versión «poblacional», la «eficacia biológica»). Los conocimientos actuales sobre el control de la información genética (Herbert, 2004) nos informan de un modo irrebatible de que es un concepto espurio. No existen individuos genéticamente "más aptos» que otros o que tengan una «ventaja genética» sobre sus congéneres. Y no es algo que sea susceptible de distintas interpretaciones: el pool genético de una especie es esencialmente el mismo (Mattick, 2004) y el significado de la variabilidad poblacional es adaptativo (en el sentido de respuesta al ambiente) pero no evolutivo. De igual forma, la variabilidad existente en los polimorfismos de nucleótido único (SNPS) es irrelevante desde el punto de vista de la evolución (Pennisi, 1998; Nadeau, 2002; Göring, 2002) y su significación es, en todo caso, demográfica: Las diferencias en vigor, salud, capacidad reproductiva, etc., de los miembros de una especie viene determinada fundamentalmente por las condiciones ambientales en que se desarrollan (Hall, 2003). Los individuos normales, sanos, no son genéticamente más o menos aptos y las mutaciones (en el caso de que no resulten inocuas) no conceden ventajas heredables, sino patologías heredables porque son desorganizaciones producidas por algún factor ambiental lo suficientemente grave para superar los eficaces mecanismos de reparación de los genomas (Kafri et al., 2005; Hirano, 2005)» $\rangle^{64}$.

En relación a la evolución, Sandín mantiene una hipótesis totalmente heterodoxa. Como se mencionó, evolución se refiere a cambios de la organización estructural de un organismo. Este tipo de cambio, según él, no puede ser gradual pues se trata de un fenómeno extremadamente coordinado que afecta simultáneamente a todo el organismo. Esta organización es determianda en etapas muy tempranas del desarrollo embrionario y casi no está sujeta a mutaciones aleatorias. Sandín defiende un cambio brusco de la organización en determinados momentos de la historia de la vida y propone el término «transformación» para estos episodios. Por lo tanto, para él no existe una evolución gradual a partir de pequeñas modificaciones en los seres vivos, sino cambios bruscos y episódicos en la estructura de los organismos, que caracterizan el surgimiento de nuevas especies.

64 SANDín, M. (2005). 
Si la idea se encuentra bastante fuera de la ortodoxia teórica de la evolución, al menos está en sintonía con el registro fósil (una de las principales bases empíricas de cualquier teoría de la evolución). Sandín utiliza los datos de la paleontología para confirmar su hipótesis de que la evolución ocurre tal como el registro fósil nos revela: cambios bruscos, en episodios específicos y sin fases intermedias ${ }^{65}$. Pero con un detalle importante: estos cambios en la organización de los seres vivos fueron acompañados por cambios bruscos en las condiciones ambientales. Esta presión del medio provoca reacciones diversas en los organismos que pueden generar cambios de carácter evolutivo.

A partir de esta proposición, no habría ningún proceso de selección natural, ya que lo que surge de estos episodios de transformación, en palabras de Sandín, «o es viable o no es nada». De nuevo, la selección natural es tan sólo el nombre de un proceso trivial y lógico: si la vida depende de una sintonía con el medio en el cual se realiza, sólo se mantendrá si existe un acoplamiento de la estructura del organismo con el medio en el que vive. Ya comenté anteriormente que, aunque ella misma no lo reconozca, ocurre lo mismo con el concepto de selección natural de Margulis. Asimismo, la competencia, concepto valioso para el darwinismo, deja de ser un componente de la evolución, mientras que el azar pierde su carácter de razón misteriosa de la complejidad de la vida ${ }^{66}$.

Pero ¿cuál sería entonces el mecanismo de estas transformaciones? Sustentándose en numerosas investigaciones (todas debidamente citadas en sus artículos), Sandín propone que los virus son la respuesta para el enigma de la evolución. La cantidad de virus endógenos y elementos móviles (de indudable origen viral) identificados en el genoma de animales y plantas (inclusive del ser humano) es la base para que Sandín marque su papel fundamental en la evolución. «(Una) nueva especie surgiría repentinamente, mediante un cambio sustancial (tal como se observa en el registro fósil) y común a un considerable número de individuos «infectados», lo que haría posible su interfecundidad. La Selección Natural ya no sería la "fuerza impulsora» de la evolución. Simplemente sería el mecanismo de eliminación de los diseños defectuosos durante los larguísimos periodos de estasis evolutiva, durante la cual, los individuos aptos (no los «más aptos») se reproducirían sin mayores problemas, y con variaciones en aspectos no esenciales (en cuyo origen, por otra parte, no se pueden descartar los «errores de copia» de los retrovirus) ${ }^{67}$.

$\begin{array}{ll}65 & \text { SAndín, M. (2004). } \\ 66 & \text { SAndín, M. (1997). } \\ 67 & \text { SANDín, M. (1997). }\end{array}$ 
En resumen, para Sandín las bacterias serían «la semilla de la vida» que contribuyen con los procesos celulares básicos que se mantienen hasta la actualidad. La contribución de los virus fue aportar los programas embrionarios y los procesos de regulación genética de las eucariotas. En el genoma de los seres vivos se encuentran muchos virus endógenos con su secuencia completa y muchos otros elementos de origen viral con modificaciones en sus secuencias. Sandín afirma que todos los genes que no son de origen bacteriano son de origen viral. Más del $95 \%$ del genoma humano está formado por virus endógenos, elementos móviles y secuencias repetidas. Los dos últimos se derivarían de virus que perdieron (algunos no) los genes que codifican la cápsida.

Los transposones (elementos que cambian de localización en el genoma) se derivan de virus ADN y los retrotransposones (que son responsables de la formación de las secuencias repetidas) se derivan de los retrovirus. Los genes que controlan el desarrollo embrionario son secuencias repetidas y por lo tanto seguramente de origen viral.

Antes se pensaba que la mayor parte del genoma estaba inactivo, por el hecho de que no codifica proteínas. Hoy se sabe que tiene una función esencial para las funciones celulares (además de tener una función reguladora, componen una totalidad interactiva). Además, conforme explica Sandín, todos los elementos de origen viral que componen esa parte del ADN también pueden activarse a través de agresiones ambientales, radiación, deficiencia o exceso de nutrientes y hasta estrés emocional. Estos hechos fueron confirmados experimentalmente ${ }^{68}$. Curiosamente, hay registros de disturbios ambientales que acompañan la aparición de nuevas especies en la historia de la vida. Asimismo, las diferencias genéticas de grandes grupos de seres vivos que surgieron tras estos incidentes se caracterizan por la duplicación (a mayor o menor escala) y reorganización genómica - características que se adaptan bien a la hipótesis de Sandín, pero que difícilmente encajan con las mutaciones lentas y al azar. Las bacterias y los virus, en la propuesta de Sandín, son los componentes fundamentales de la vida. Su conversión en organismos patógenos sería una respuesta a agresiones en el ecosistema que alteran el equilibrio natural.

Por lo tanto, su idea es que los virus, gracias a su capacidad de «infección», que permite una transmisión horizontal del material genético, y su capacidad de insertarse en genomas, permanecer inactivos y reactivarse, de hacer copias de sí mismos insertándolas en ciertos lugares del ADN y su movilidad, permiten una constante reorganización del genoma, que resulta en el

68 Cf. SANDín, M. (1997). 
surgimiento de nuevos organismos a partir de la transformación de los ya existentes. Esto explicaría la evolución (cambios de organización) a partir de un nuevo concepto, radicalmente diferente del concepto darwinista. Además, y esto es lo más importante, completamente sustentada sobre datos reales y capaz de explicar numerosos fenómenos que no encajan bien en la simplicidad de las mutaciones aleatorias y la selección natural.

La propuesta de Sandín posee las condiciones necesarias para ser candidata a un nuevo paradigma. Está ampliamente amparada por datos científicos, explica una serie de cuestiones que son anomalías en el paradigma hegemónico y, al mismo tiempo, abre un nuevo campo de investigación para la biología. Sin embargo, para aceptarla, es preciso reconocer la completa incapacidad del darwinismo para explicar el fenómeno de la vida y sustituir su visión del mundo por otra, basada tanto en datos como en una concepción diferente de la naturaleza. Esto, ciertamente, no es tan simple. Como afirma Kuhn (y contra lo que habitualmente la ciencia da por hecho) el apego a un paradigma no tiene una motivación racional sino que se trata un proceso de «conversión». A pesar de lo que intentó afirmar Lakatos ${ }^{69}$, la elección de un programa de investigación no es una opción consciente a partir de la constatación de la degeneración de un programa anterior y de la fecundidad de uno nuevo. La adhesión al darwinismo involucra cuestiones doctrinales e ideológicas, tal vez hasta más que científicas.

\section{CONCLUSIÓN}

De acuerdo a lo que afirmé al inicio de este artículo, la ciencia es una construcción constante de conocimientos acerca de la naturaleza, que resulta del diálogo dinámico entre la conciencia humana y el mundo a su alrededor. Para que este diálogo se vuelva inteligible e intercomunicativo establecemos ciertos «protocolos», a partir de los cuales la información del mundo real es interpretada y entendida por una colectividad de científicos y por la sociedad. En este sentido, cuando nos referimos a una teoría científica no estamos hablando de un «descubrimiento», sino de una síntesis racional que orienta y, al mismo tiempo, se alimenta del trabajo experimental (que proporciona tanto la base factual como el contexto problemático que ponen en movimiento a la ciencia). La ciencia es, por eso, una actividad de interpretación (en el nivel conceptual) del mundo natural a partir de una síntesis teórica.

69 LAKATOS, I. (1979), «O falseamento e a metodologia dos programas de pesquisa». In:. LaKatos, I.; Musgrave, A. (1979). p. 109-243. 
Por ser una relación dinámica y dialéctica con la naturaleza (y no un registro acumulativo de hechos), la ciencia trabaja creando paradigmas, concepto introducido en la epistemología por Thomas Kuhn. La relación es dinámica por estar siempre en movimiento - las teorías científicas no son estáticas- y porque puede ser alterada por un conjunto de factores que comprenden la producción científica: historia, interés social, tecnología, ampliación de la base fáctica e «insights» emblemáticos del genio humano. Es dialéctica por involucrar en una relación de determinación reflexiva a dos polos que, en el aspecto ontológico (es decir, el de la realidad inmediata de cada uno), no se reducen uno al otro: la subjetividad humana y el comportamiento en si de la naturaleza. Estos dos polos se unen y, al mismo tiempo, mantienen una autonomía relativa en el plano gnoseológico (es decir, del conocimiento).

Por ser dialéctica, la ciencia necesita tanto de las teorías como de las experiencias. Datos sin teoría no constituyen ciencia - el Renacimiento, por ejemplo, fue provechoso en datos, pero no creó ciencia. También dejan de ser científicas las teorías que pierden el apoyo o el control de los datos, ya sea por falta de base factual, por contradicciones obvias con los datos disponibles o por incapacidad de explicar los datos conocidos.

Los factores mencionados que ponen en movimiento a la ciencia, haciéndola dinámica, merecen un análisis aparte pero podemos resumirlos en una reflexión breve. La historia se caracteriza por el dominio de ciertos procesos civilizadores que traen consigo una forma de producción, un patrón de sociabilidad, una ética y una ontología (concepción sobre el ser de la realidad), que definen ciertas concepciones generales acerca de la naturaleza, del universo y del ser humano. Las variaciones en la forma concreta de existencia de estas concepciones generales y las divergencias que siempre se manifiestan de forma no hegemónica no son suficientes para impedir que se identifique en periodos históricos la forma general, forma que caracteriza la presencia del ser humano en el mundo. Por eso es posible distinguir los patrones que se manifestaron en la antigüedad clásica, en los imperios helénico y romano, en la Edad Media y en la Modernidad. Asimismo, es fácil identificar la característica de transición en ciertos periodos de la historia, tal como el Renacimiento.

Este patrón de ser y pensar constituye una racionalidad general que orienta la interpretación del mundo y, por eso, concede una peculiar configuración al conocimiento en todas sus expresiones: filosófica, científica, artística, religiosa y de sentido común. Por lo tanto, la ciencia siempre está marcada por ser expresión de una racionalidad hegemónica en la investigación de la naturaleza ${ }^{70}$. Sus

70 Con respecto a las concepciones generales que orientaron el surgimiento de la ciencia moderna y de la vinculación entre la ciencia y concepciones generales de mundo (metafísicas 
teorías llevan consigo la marca de la historicidad del ser humano. Por esto, siempre será una actividad histórica, justamente por ser una actividad humana.

El interés social ${ }^{71}$ encausa la aplicación de recursos (públicos y, principalmente, privados) y el interés de la comunidad científica por ciertas áreas de investigación y contribuye a la aceptación de paradigmas. La ciencia no está por encima de las relaciones de poder en la sociedad, sino que por el contrario, sufre los efectos de esta relación. Así como existía una estrecha vigilancia en la Rusia estalinista sobre la producción científica que negaba, o simplemente no legitimaba, los principios de la doctrina oficial del estado soviético, existe también cierto control no estatal (y no visible) en relación a los principios del liberalismo y del mercado. Basta ver lo que se invierte en «ciencia aplicada» (léase de utilidad a las grandes corporaciones que dominan el mercado) y cómo se divulga — de forma masiva, cual doctrina - , cualquier propuesta que pretenda transformar la competencia en ley natural y presentar las diferencias sociales y el comportamiento violento del ser humano como resultados de un determinismo biológico.

En un comentario sobre la sociobiología, Stephen Jay Gould afirma: «El prolongado e intenso debate en torno al determinismo biológico surgió en función de su mensaje político y social. [...] El determinismo biológico siempre fue usado para defender situaciones sociales ya existentes, calificándolas de biológicamente inevitables. ¿Por qué otra razón un conjunto de opiniones tan desprovisto de evidencias directas puede adquirir una cobertura tan consistente y favorable en los medios de comunicación "establecidos», a través de los siglos?» 72

No obstante, la cantidad de artículos científicos sobre el comportamiento social de los seres humanos, en publicaciones especializadas de renombre, muestra que éste no es un fenómeno exclusivo de los «mass media». Artículos científicos que pretenden entender el altruismo humano dentro de la «lógica competitiva de la evolución» y lo someten a esta lógica pueden ser encontrados en diversas publicaciones importantes ${ }^{73}$.

y teológicas) que caracterizaron periodos históricos, ver THUILLIER, P. (1994); KOYRÉ, A. (1991), Estudos de história do pensamento científico. Rio de Janeiro, Forense Universitária; Rossi, P. (1992), A ciência e a filosofia dos modernos, São Paulo, Edunesp; BuRTT, E. A. (1991), As bases metafisicas da ciência moderna, Brasília, Editora da UnB; e HARRÉ, R. (1988), As filosofias das ciências, Lisboa, Edições 70.

${ }^{71}$ Aquí interés social no se refiere a los intereses de la mayoría de la sociedad, sino a los intereses que resultan de las relaciones de poder y hegemonía en una sociedad.

72 Gould, S. J (1999), p. 256.

73 Ver, por ejemplo, DANIELSON, P. (2002), «Competition among cooperators: altruism and reciprocity», Proceedings of the National Academy of Science of United States of America, 99, 
La tecnología amplía la capacidad de «ver» fenómenos que antes estaban ocultos a los sentidos humanos y, la mayoría de las ocasiones, abre un nuevo campo fenomenológico que impulsa a la ciencia a reajustarse, produciendo un movimiento en las teorías científicas y hasta crisis de paradigmas. Instrumentos como los radiotelescopios y telescopios de rayos X, el espectrómetro, el microscopio electrónico, la cristalografía de rayos X, etc., ampliaron considerablemente el campo fenomenológico con el que trabaja la ciencia y revelaron partes de la realidad que se ocultaban de los sentidos y que no siempre eran previstas por las teorías válidas.

La ampliación de la base fáctica de la ciencia es el resultado tanto de la tecnología como del alcance de las teorías. La matemática, por ejemplo, es capaz de aportar dimensiones espaciales y fenómenos virtuales que antes no pertenecían al dominio de determinadas ciencias ya que no eran accesibles a la imaginación humana. La función de onda en la mecánica cuántica y las numerosas dimensiones especiales de la teoría de las Supercuerdas son ejemplos de este hecho ${ }^{74}$. Asimismo, teorías que antes pertenecían a una sola área de la ciencia se ampliaron con la contribución de otras dada la interrelación entre el campo fenoménico estudiado. Por ejemplo, la Biología en relación con la Química y Física, la Química en relación con la Física, etc. Al ampliar el campo de objetos que se investiga, las teorías también se modifican.

Los insights emblemáticos del genio humano se refieren al papel de la inventiva y creatividad de determinados científicos que, con sus propuestas, con frecuencia insólitas, contribuyeron con ideas notables hasta el punto de influir las teorías y poner a la ciencia en movimiento. La historia de las ciencias nos provee de tantos ejemplos que nos ahorraremos el mencionarlos.

La teoría de evolución de Darwin es una teoría científica. Así fue recibida por la comunidad científica y se constituyó en un paradigma. Como tal, está sujeta a todos los factores que actúan sobre cualquier teoría en la ciencia, colocándolas en movimiento y, muchas veces, derrumbándolas. Conforme a lo que se dijo en este documento, el darwinismo está sometido a su aspecto histórico, de interés social, de los avances de la tecnología y de la ampliación de la base fáctica de la Biología. Nuevos insights pueden también colocar a la Biología en movimiento y no necesariamente en el sentido de reforzar al paradigma hegemónico. El vínculo del darwinismo con la racionalidad domi-

7237-7243; KURZBAN, R. \& HOUSER, D. (2005), «Experiments investigating cooperative types in humans: A complement to evolutionary theory and simulations.» Proceedings of the National Academy of Science of United States of America, 102, 1803-1807; entre decenas de otros.

74 Cf. Greene, B. (2001), O universo elegante, São Paulo, Companhia das Letras. 
nante, claramente de orientación liberal, conforme afirma el propio Darwin, es un aspecto que debe considerarse seriamente para distinguir el carácter histórico y de interés social de esta teoría.

A través de las reflexiones de Behe, Margulis y Sandín, pudimos ver los serios problemas que el darwinismo ha encontrado en el campo científico. También vimos la connotación ideológica y doctrinaria que tal teoría asumió cuando sus exponentes hicieron frente a las críticas de Behe. Eso significa que a pesar de que la ciencia, considerada como una actividad humana, es dinámica y dialéctica, no aparece necesariamente de esta forma en la cabeza de los científicos. Esto ya fue objeto de las reflexiones filosóficas de Bachelard, con su concepto de obstáculo epistemológico, ${ }^{75}$ y de Thomas Kuhn, con su afirmación de que el apego a un paradigma no tiene motivaciones racionales ${ }^{76}$. Sin embargo, este riesgo ya estaba presente en las reflexiones de Bacon sobre los ídolos, que impiden el avance del conocimiento ${ }^{77}$.

Es posible, por lo tanto, suponer enérgicamente que la pregunta hecha en la introducción (¿será Darwin para el siglo veintiuno lo que Newton fue para el siglo veinte?) tendrá una respuesta afirmativa, a partir de la solidez y consistencia de la crítica dirigida al darwinismo y dado el avance de la historia. Pero imaginar que este proceso de crisis y revolución será fácilmente digerido por los científicos es una enorme ingenuidad. Las nuevas generaciones de científicos (específicamente en el campo de las ciencias biológicas, pero sin excluir otros como los de la física y la química) tienen el desafío de mantener lo científico en la ciencia. Esto implica un desafío doble, de orden científico y filosófico: un esfuerzo por acomodar las teorías al ámbito factual que pretenden explicar — desafío de orden científico- $\mathrm{y}$, al mismo tiempo, percibir lo dinámico y dialéctico de la empresa científica, evitando etiquetarlas como «descubrimiento» y «revelación de la verdad» de la naturaleza - lo que representa un desafío de orden filosófico.

La crisis del darwinismo no significa un regreso a las concepciones que precedieron al naturalismo, entendido como la búsqueda de causas naturales para los fenómenos naturales; inclusive porque Darwin no responde a la paternidad de esta empresa: varios científicos anteriores a él también buscaron causas naturales para la evolución ${ }^{78}$. Lo que puede cuestionarse a partir de

75 Bahelard. G. (1996). A formação do espírito científico, Rio de Janeiro, Contraponto.

76 KUHN, T. (1979a; 1979b).

77 BACON, F. (1973), Novum organum, São Paulo, Abril Cultural. La peculiaridad de Bacon, que hoy, lejos de su tiempo, podemos juzgar ingenua, es que él creía posible que nos librásemos totalmente de los ídolos. La ciencia, para él, sería una actividad totalmente imparcial, en virtud de la depuración de los obstáculos de la subjetividad humana.

78 Ver SANDín, M. (2002a), «Hacia una nueva Biología», Arbor, 677, 167-218. 
esta crisis es el reduccionismo, mecanicismo y determinismo que caracterizaron a la ciencia moderna. Esto, no obstante, tan sólo refuerza el cuestionamiento trazado por la física del siglo veinte.

Lo que parece configurarse en el escenario de la ciencia es un cambio radical de enfoque en la investigación, fruto de la comprobación de la complejidad estructural de la vida referida en el inciso 3 de este artículo. En lugar de enfocarse en la estructura molecular de las partes que componen la célula (siguiendo el reduccionismo neodarwinista), las nuevas maneras de abordar el problema canalizan su análisis en el comportamiento colectivo de esas partes. En otras palabras, en vez de la materia que constituye la vida, se le da importancia a la relación entre los elementos. Es esta relación la que constituye la totalidad organizada de la vida y, aunque dependa de la materialidad de las moléculas básicas que forman a los organismos vivos, no se revela a partir de las características individuales de sus partes constituyentes. Así se explica que todo el trabajo que busca comprender la vida a partir de las informaciones obtenidas de los nuevos descubrimientos en el campo de la bioquímica, de la microbiología, así como de las mayores informaciones sobre la estructura del genoma, recurren a las ideas de complejidad y autoorganización, creando las condiciones para el establecimiento de un nuevo paradigma.

Para aquellos que serán testigos del siglo veintiuno, es bastante probable que acontezca una nueva revolución en las ciencias. Esta vez, en lugar de la Física, la gran protagonista será la Biología. Cambios similares han ocurrido otras veces en la historia y no significan corrección de errores, sino transición de paradigmas. De la misma manera que la historia de las ciencias registra estas revoluciones, también nos recuerda la resistencia de los sectores más conservadores a este cambio. Los responsables de la Inquisición, en nombre de principios sagrados fundados en el aristotelismo (más que en la Biblia), cometieron actos que hasta hoy nos repugnan. Los hombres y mujeres de la ciencia de hoy (y también de la Filosofía) deben decidir si su manera de tratar la ciencia y su apego a principios sagrados los haga ser recordados como los inquisidores del siglo veintiuno, o si uno de los motores de una nueva ciencia será justamente su capacidad de rescatar el espíritu naturalista, no dogmático, y de percibir la eterna transitoriedad de los paradigmas.

Fecha de recepción: 12 de junio de 2005

Fecha de aceptación: 20 de enero de 2006 
